\title{
Low Pressure Systems and Extreme Precipitation in Southeast and East Asian Monsoon Regions
}

\author{
YuJiA YOU ${ }^{\mathrm{a}, \mathrm{b}}$ AND MingFAnG Ting ${ }^{\mathrm{a}}$ \\ ${ }^{\mathrm{a}}$ Lamont-Doherty Earth Observatory, Columbia University, Palisades, New York \\ ${ }^{\mathrm{b}}$ Department of Earth and Environmental Sciences, Columbia University, Palisades, New York
}

(Manuscript received 23 March 2020, in final form 17 August 2020)

\begin{abstract}
Understanding the physical mechanisms behind the secular trends of summer rainfall extremes over the heavily populated Southeast and East Asian monsoon regions is not only of scientific importance but also of considerable socioeconomic implications. In this study, the relevance of the excessive-rain-producing low pressure systems (LPSs) to extreme rainfall is quantified. Using an objective feature-tracking algorithm, the synoptic-scale LPSs are identified and tracked in the 40-yr ECMWF interim reanalysis. The region experiences approximately 16 terrestrial and 18 marine LPSs each summer. The terrestrial LPSs form near the downwind side of the Tibetan Plateau and travel northeastward toward jet latitudes. The marine LPSs form over the western North Pacific Ocean and migrate along the western periphery of the subtropical high. While both types of LPSs account for a large portion of upper-tail rainfall, the terrestrial LPSs predominantly impact the extreme rainfall over inland areas, and the marine LPSs primarily affect the coastal regions where they frequently make landfall. The historical extreme rainfall trend during 1979-2018 aligns with the changes in LPS tracks. The decreasing number of northeastward-moving terrestrial LPSs leads to an extreme rainfall dipole with negative trends in north-central China and positive trends in southern China, while the increasing number of northward-recurving marine LPSs enhances the extreme rainfall in the eastern China coast but suppresses it over the South China Sea. These trends are driven dynamically by the weakening of the monsoonal southwesterlies and the eastward retreat of the subtropical high, which might be attributable to anthropogenic forcings.
\end{abstract}

KEYWORDS: Asia; Extratropical cyclones; Extreme events; Monsoons; Rainfall; Tropical cyclones

\section{Introduction}

Investigating the physical processes underlying the longterm changes in extreme rainfall has profound socioeconomic implications, especially for the densely populated Asian monsoon regions. The synoptic low-pressure systems (LPSs), which occur frequently over the Asian summer monsoon regions, are among the most important weather systems for producing excessive precipitation and hazardous floods that cause severe damages to human lives and properties (e.g., Pfahl and Wernli 2012; Hurley and Boos 2015; Singh et al. 2019). In the present study, the LPSs are broadly defined as synoptic-scale cyclonic vortices with atmospheric pressure lower than the surrounding areas. In the Southeast and East Asian monsoon regions, the most well-known LPSs are tropical cyclones (TCs), which form over the western North Pacific (WNP) and migrate along the southern and western periphery of the subtropical high. To what extent the WNP TCs shape the regional rainfall characteristics has received considerable attention. Based on various satellite and rain gauge measurements, it is generally accepted that TCs account for $40 \%-50 \%$ of the summer rainfall totals and around $70 \%$ of the rainfall extremes in the coastal regions where TCs typically make landfall (Jiang and Zipser 2010; Guo et al. 2017). However, the impact of TCs in these regions is largely constrained to a narrow stretch along the shoreline (e.g., Khouakhi et al. 2017; Liang et al. 2017; Zhang et al. 2018).

Corresponding author: Yujia You, yujia@ldeo.columbia.edu
In addition to TCs formed over open oceans, LPSs that originate over land are particularly active in the East Asian monsoon region owing to the mechanical forcing of the plateau orography and the humid, convectively unstable monsoon environment (Wang and Orlanski 1987; Wang et al. 1993). Specifically, the Tibetan Plateau splits the midlatitude westerlies into two branches north and south of the plateau. The resulting cyclonic vorticity cell downstream of the southern branch enhances the occurrence of vortex disturbances (e.g., Wu et al. 2007). The two branches converge around $1000 \mathrm{~km}$ east of the plateau where the monsoonal southwesterlies deliver warm and moist air northward, creating strong meridional and vertical equivalent potential temperature gradients on the equatorward flank of the subtropical jet entrance. These conditions work together to provide a large-scale environment conducive to cyclogenesis over the downwind side of the Tibetan Plateau. In the local meteorological community, the land-based LPSs are referred to as the Southwest Vortex, JiangHuai Cyclone, Huang-Huai Cyclone, etc., based on their specific genesis locations. Although these terrestrial LPSs have long been recognized as important drivers of extreme rainfall, observationbased track archives are not readily available partly owing to the lack of rigorous identification criteria and the dearth of long-term observations. Most existing studies examined the structure and impact of these storms based on a single event or very short records (e.g., Tao 1980; Tao and Ding 1981; Wang et al. 1993). We are not aware of any thorough investigations that have analyzed a large number of systems, except that Fu et al. (2014) and Feng et al. (2016) assessed the climatology of southwest vortices using the Climate Forecast System Reanalysis (CFSR). The spatial and 

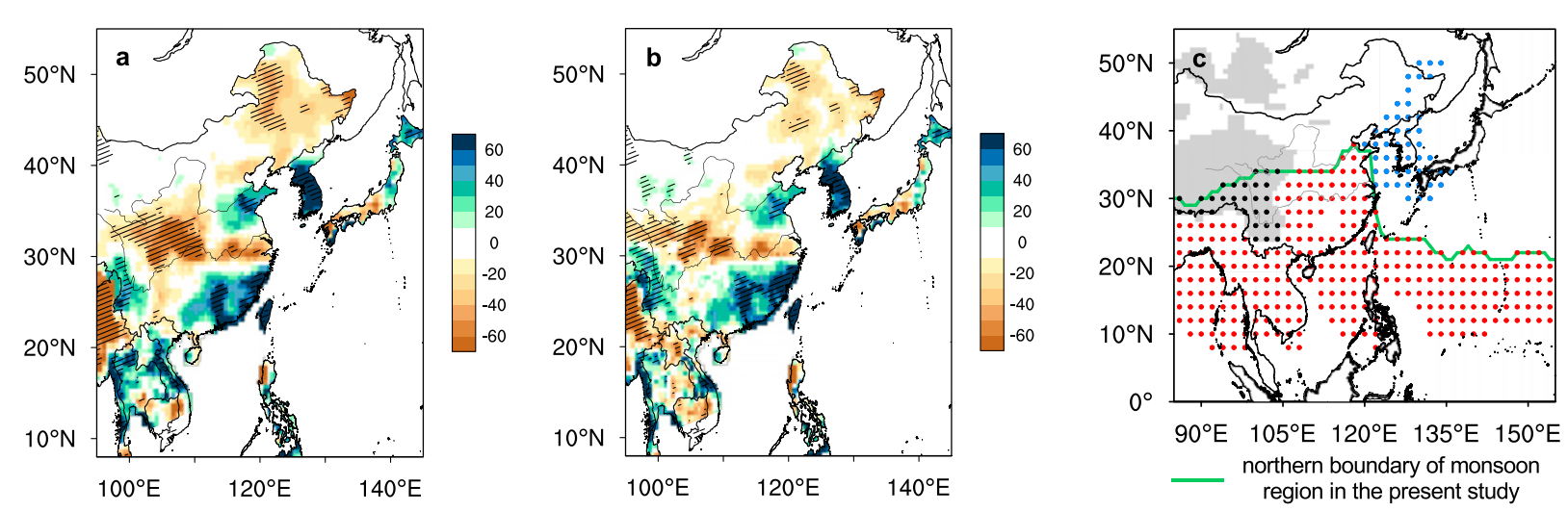

FIG. 1. Linear trends (mm decade ${ }^{-1}$; shading) of the summer (MJJAS) (a) seasonal rainfall totals and (b) extreme daily rainfall amounts from 1979 to 2007. Rainfall is taken from APHRODITE. Extreme daily rainfall here is defined as exceedances of the local 90 th percentile. Hatching in (a) and (b) indicates confidence at the $90 \%$ level with a nonparametric Mann-Kendall test. (c) Asian monsoon region in which the local summer (MJJAS) minus winter (NDJFM) precipitation rate exceeds $3.0 \mathrm{~mm} \mathrm{day}^{-1}$ and the local summer precipitation exceeds $55 \%$ of the annual total (dotted region). The blue dotted region is excluded from the Asian monsoon region (see text) and the green solid line outlines the northern boundary of the defined Asian monsoon domain in this study. Regions where the 850-hPa pressure level falls below ground are denoted by black dots and gray shading.

temporal variability of terrestrial LPSs and their relationships with regional rainfall extremes have not been fully quantified from a climatic perspective.

Previous observational studies have documented a statistically discernible dipole trend in the summer rainfall totals over China since the mid-twenty-first century with decreasing trends in central-northern China and increasing trends in southern China (Fig. 1a; Wang and Zhou 2005; You et al. 2011; Ma et al. 2015; Day et al. 2018). This rainfall trend, referred to as the "south flood-north drought" pattern, is primarily driven by the changes in the uppermost quantiles of daily rainfall (Fig. 1b; Liu et al. 2005; Zhai et al. 2005; Dong et al. 2011). Exploring the changes in daily rainfall extremes is thus essential for understanding the root causes of the summer rainfall trends. Although several mechanisms have been proposed to explain this dipole pattern, such as the weakened summer monsoon circulation (Wang and Zhou 2005), the anomalous anticyclone over Eurasian continent (You et al. 2011), and the shift of the East Asian jet stream (Day et al. 2018), it remains unclear how these mechanisms, which operate on seasonal time scale and larger spatial scales, influence the daily rainfall extremes. Given the association between synoptic LPSs and extreme rainfall (e.g., Hurley and Boos 2015; Khouakhi et al. 2017), it is reasonable to hypothesize that the spatiotemporal variations of monsoon rainfall extremes are, to a certain extent, driven by corresponding changes in LPS activities. A number of previous studies have reported a poleward migration of the WNP TC trajectories (e.g., Wu et al. 2005; Tu et al. 2009; Chang et al. 2012; Chu et al. 2012; Kossin et al. 2016; Zhang et al. 2018), which has contributed to the extreme rainfall trends along the coastal areas (Ren et al. 2006; Li and Zhou 2015; Liang et al. 2017). However, how the excessive rain-producing LPSs acted as the drivers of extreme rainfall trends over the vast inland areas has not yet been explored.

The present study attempts to build the connection between the synoptic LPSs and extreme rainfall to gain deeper insight into their spatial and temporal covariations. In particular, we focus on LPSs that form over land as compared to those that form over oceans, in order to understand the broad dipole pattern of the extreme precipitation trend over the landmass (Figs. 1a,b). As the properties of LPSs are modulated by the ambient environments, this process-based approach can also help better quantify the contribution of large-scale background flow to daily extreme rainfall. As such, whether the dipole trend pattern is part of the emerging anthropogenic signals or natural internal variabilities could be better understood. The rest of the paper is organized as follows. Section 2 introduces the data and methods used in this study. Section 3 describes the characteristics of monsoon LPSs. The connections between LPS and extreme rainfall, especially regarding the long-term trends, are examined in section 3 , followed by a discussion of the dynamic mechanisms driving the long-term LPS trends in section 4. The main conclusions are summarized in section 5 .

\section{Data and method}

\section{a. Data}

To track the monsoon LPSs and to investigate the connections between LPSs and extreme precipitation, the European Centre for Medium-Range Weather Forecasts (ECMWF) interim reanalysis (ERA-Interim, herein ERA-I) 6-hourly dataset for the years 1979-2018 is employed (Dee et al. 2011). Variables used in the current study include sea level pressure 
(SLP), geopotential height, wind, relative vorticity, and air temperature. The data are on the N128 Gaussian grid $(\sim 70 \mathrm{~km})$ with 32 pressure levels ranging nonuniformly from 1000 to $10 \mathrm{hPa}$. The precipitation spaced on a $0.5^{\circ} \times 0.5^{\circ}$ latitude-longitude grid globally is taken from the short-range forecast accumulations and is aggregated into daily data. The ERA-I precipitation is employed because of the physical consistency with the reanalysis-based atmospheric circulation, especially along the reanalysis-derived LPS trajectories. Furthermore, ERA-I has been shown to have the best skill in reproducing the monsoon precipitation climatology among various reanalysis products (Lin et al. 2014). For comparison, we utilize a compilation of gauge-based gridded daily precipitation dataset, the Asian Rainfall Highly-Resolved Observational Data Integration Toward Evaluation of Water Resources (APHRODITE; Yatagai et al. 2012). The APHRODITE_ MA_v1101 product covers the period 1951-2007 and contains gridded daily precipitation over the Asian landmass on a $0.5^{\circ} \times 0.5^{\circ}$ horizontal grid. As the two rainfall products are both gridded data, here we essentially focus on the rainfall with a spatial scale larger than $\sim 2500 \mathrm{~km}^{2}$. A detailed comparison of precipitation extremes between ERA-I and APHRODITE as well as several other datasets can be found in Kim et al. (2019).

\section{b. LPS tracking algorithm}

An objective feature-tracking algorithm (TRACK) emulating the manual tracking procedure was implemented to compile the trajectories of monsoon LPSs. Since a detailed description of TRACK is given in Hodges (1994, 1995, 1999), here we briefly introduce the key features. In the present study, the tracking algorithm is applied to the ERA-I 6-hourly 850 -hPa relative vorticity field. We choose relative vorticity, rather than SLP or geopotential height, because vorticity is less influenced by the large-scale background flow. The drawbacks of using SLP and geopotential height were discussed in Hoskins and Hodges (2002). To extract the synoptic-scale features, total wavenumber smaller than 5 and larger than 42 is spectrally filtered out from the vorticity field using triangular truncation, and subsequently a spectral taper is applied to reduce the Gibbs oscillations (Sardeshmukh and Hoskins 1984). The tracking algorithm proceeds by identifying the filtered vorticity maxima exceeding a threshold of $5 \times 10^{-6} \mathrm{~s}^{-1}$ at each time step. The vorticity maxima in consecutive time steps are connected using a nearest-neighbor approach to construct the initial LPS trajectories. The trajectories are then refined by minimizing a cost function subject to adaptive constraints on displacement distance and track smoothness (Hodges 1999). The endpoint merging, which connects splitting trajectories by searching for overlapping start and endpoints, is also performed. Spurious short-lived systems with a lifespan shorter than eight time steps (2 days) are removed.

A post-tracking filter is applied by adding the 6-hourly SLP anomaly (SLPA) to provide an intensity criterion. In this case, the SLPA is defined as the deviation from 21-day running mean and is truncated at wavenumber 63 to remove anomalies associated with intraseasonal and lower-frequency variabilities (Hurley and Boos
2015). The post-tracking filter searches for negative SLPA minimum within $500 \mathrm{~km}$ of the vorticity maximum. Furthermore, the SLPA minimum and vorticity maximum must be surrounded by at least one closed SLPA convex ${ }^{1}$ contour, within which the averaged SLPA gradient must exceed $2 \mathrm{hPa}(500 \mathrm{~km})^{-1}$. The vorticity maxima and SLPA minima beneath Earth's surface are neglected. Only systems that have at least one track point satisfying all these post-tracking criteria are retained. The sensitivity of LPS trajectories to the convexity and SLPA gradient threshold was tested systematically (not shown).

The monsoon domain is identified by rainfall characteristics (e.g., Wang et al. 2012), namely, the local summer-minuswinter precipitation exceeding $3.0 \mathrm{~mm} \mathrm{day}^{-1}$ and the local summer precipitation exceeding $55 \%$ of the annual total (dotted region in Fig. 1c). To remove systems that form and reside mostly in the midlatitude westerlies outside the monsoonal flow, the blue dotted region in Fig. 1c is excluded from the monsoon domain. The monsoon LPSs are therefore defined as the cyclones that have at least four track points (1 day) equatorward of the northern boundary of the adjusted monsoon region (green line in Fig. 1c). Indian monsoon LPSs, which spend most of their life cycle to the west of $100^{\circ} \mathrm{E}$, are not considered in this paper. In summary, the following identification criteria need to be satisfied to be considered as a monsoon LPS:

1) The spectrally filtered (total wavenumbers 5 to 42 ) relative vorticity at $850 \mathrm{hPa}$ reaches a magnitude of at least $5 \times 10^{-6} \mathrm{~s}^{-1}$.

2) It lasts longer than 2 days and spends at least one day in the predefined Southeast and East Asian monsoon regions.

3) The relative vorticity maximum coexists with a SLPA minimum within $500-\mathrm{km}$ radius in at least one time step.

4) The relative vorticity maximum and SLPA minimum are enclosed by closed SLPA convex contours, within which the SLPA gradient is at least $2 \mathrm{hPa}(500 \mathrm{~km})^{-1}$.

The identified systems are grouped into terrestrial and marine LPSs based on their genesis locations. We test the reliability of the tracking algorithm by comparing the marine LPSs trajectories with those WNP TC trajectories from the International Best Track Archive for Climate Stewardship dataset (IBTrACS; Knapp et al. 2010). More than $90 \%$ of the observed WNP TCs are successfully captured by the tracking algorithm (not shown).

\section{c. Statistical attribution technique for changes in LPS track density}

The genesis and track density are two of the most common measures of storm activities. Conventionally, the genesis density measures how frequently storms form in a specific region and the track density quantifies how frequently a specific region is affected

\footnotetext{
${ }^{1} \mathrm{~A}$ contour is convex if the line segments joining any pair of interior points lie entirely within the contour. For instance, ovals and circles are convex, but crescents and star-shaped polygons are not. The convexity of a contour is the difference in area between the convex hull and the contour divided by the contour's area. A contour is considered to be nearly convex when the value of convexity is small. Here the convexity threshold is set to 0.05 .
} 
by storms. In this study, the LPS genesis and track density are calculated by counting the number of LPS genesis points (i.e., first track position) and track points within $500-\mathrm{km}$ radius of each grid point each summer from May to September, respectively (Hurley and Boos 2015). As the LPS trajectories are reported at successive 6-h time intervals, the number of track points within a given area can be converted to the number of days that cyclone centers stay inside the area. Thus, we further divide the total number of track points by four to obtain track density as the total number of days LPSs staying within a 500-km radius of each grid point each summer (e.g., Vecchi and Knutson 2008). Hence, the unit of genesis density is number of LPSs per summer and the unit of track density is number of LPS days per summer.

The LPS track density is determined jointly by the genesis (both location and frequency) and propagation (both direction and speed), and the changes in genesis and propagation are often driven by different physical processes. To disentangle the relative contributions of LPS genesis and propagation to the changes in track density between two time periods, we adopted a statistical attribution technique (e.g., Murakami et al. 2013; Yokoi et al. 2013; Li and Zhou 2015). In a given period, the climatological mean track density in a specified region $A$ can be written as

$$
f(A)=\iint g\left(A_{0}\right) t\left(A \mid A_{0}\right) d A_{0},
$$

where $g\left(A_{0}\right)$ is the climatological genesis density in grid cell $A_{0}$ in number of LPSs per summer, and $t\left(A \mid A_{0}\right)$ is the average length of time for each individual LPSs formed in grid cell $A_{0}$ to stay within region $A$, expressed in number of days per summer. Therefore, $f(A)$, the track density in unit of number of LPS days per summer, is the spatial integral of the product between $g\left(A_{0}\right)$ and $t\left(A \mid A_{0}\right)$. As $g\left(A_{0}\right)$ equals zero if no LPS formed in grid cell $A_{0}$, the equation essentially integrates over all the grid cells that have nonzero LPS genesis. To reduce sampling error, $g\left(A_{0}\right)$ and $t\left(A \mid A_{0}\right)$ are calculated for every $5^{\circ} \times 5^{\circ}$ grid cell following previous works (Murakami et al. 2013). Based on Eq. (1), we can decompose the changes in track density over region $A$ between two time periods $[\Delta f(A)]$ into three terms:

$$
\begin{aligned}
\Delta f(A)= & \iint g\left(A_{0}\right) \Delta t\left(A \mid A_{0}\right) d A_{0} \\
& +\iint \Delta g\left(A_{0}\right) t\left(A \mid A_{0}\right) d A_{0} \\
& +\iint \Delta g\left(A_{0}\right) \Delta t\left(A \mid A_{0}\right) d A_{0} .
\end{aligned}
$$

The first two terms on the right-hand side of Eq. (2) represent epochal changes in track density due to changes in propagation (first term) and genesis (second term). The last term denotes a nonlinear effect produced by the covariance between changes in genesis and changes in propagation.

\section{Monsoon LPS characteristics}

The monsoon LPS activity is quantified by the genesis density, track density, and translation velocity. The translation vector is derived using the neighboring track positions at 6-hourly intervals along each trajectory. The climatological means of these quantities together with the LPS genesis locations are presented in Fig. 2 for LPSs originated over land and ocean grids separately.

On average, approximately 16 terrestrial LPSs and 18 marine LPSs impact the predefined monsoon region each summer. For terrestrial LPSs, active cyclogenesis is observed on the lee side of the Tibetan Plateau (Figs. 2a,b). The mean translation vectors point monotonically toward the northeast, in the same direction as the steering flow along the northwestern flank of the WNP subtropical high and in the confluence entrance of the East Asian jet streak (red contours in Fig. 2b). The climatological track density of the terrestrial LPSs shares a common center with the genesis density at $25^{\circ} \mathrm{N}, 110^{\circ} \mathrm{E}$ (Figs. $2 \mathrm{~b}, \mathrm{c}$ ), indicating that a portion of the terrestrial LPSs do not propagate too far away from their genesis locations. The terrestrial LPSs moved out of their genesis locations tend to travel toward the jet latitude with an increasing translation speed. By contrast, the genesis locations of the marine LPSs spread over a wider area with two local genesis maxima over the northern South China Sea (SCS) and tropical WNP ocean (Fig. 2d). The majority of the marine LPSs form on the equatorward flank of the subtropical high and are steered by the easterly trades to migrate westward (Fig. 2e). When these marine LPSs approach the western edge of the seasonal mean WNP subtropical high (i.e., to the east of Taiwan and the Philippines), the climatological track density reaches its maximum, the translation slows down, and the LPS trajectories split into two: those moving westward to make landfall in Southeast Asia and those veering northward toward eastern China, the Korean Peninsula, and Japan (Fig. 2f). On the other hand, a smaller number of marine LPSs formed over the northern SCS tend to migrate northwestward and make landfall in the coastal areas bordering the SCS. Since most of the marine LPSs dissipate quickly after making landfall, the climatological track density and translation speed diminish rapidly landward.

The profound differences in the genesis location imply that the terrestrial and marine LPSs form in very different environments, and therefore are likely distinct in their spatial structures and energy sources. The horizontal and vertical structures of LPSs are obtained by constructing the vortexcentered composites based on the anomaly fields. Here the anomaly is calculated as the 6-hourly deviation relative to the 21-day running means. For the terrestrial (marine) LPSs, only track positions over land (ocean) are considered. As some of the marine LPSs take the northward-recurving pathway and move into midlatitudes where their structures vary substantially by interacting with the baroclinic midlatitude westerlies (i.e., extratropical transition), only track positions south of $35^{\circ} \mathrm{N}$ are included in the composite of marine LPSs.

Figures 3a-d depict the composited horizontal structure, zonal and meridional cross sections of temperature, winds, rainfall, and vertical velocity for the terrestrial LPSs. A sharp northwestsoutheast elongated temperature gradient is evident in the lower troposphere (Fig. 3a), implying that the terrestrial LPSs are characterized by an enhancement of the background meridional temperature gradient. The southwesterly (northeasterly) wind anomalies in the southeastern (northwestern) quadrant advect warm (cold) and moist (dry) air masses from lower (higher) latitudes, giving rise to the low-level temperature 

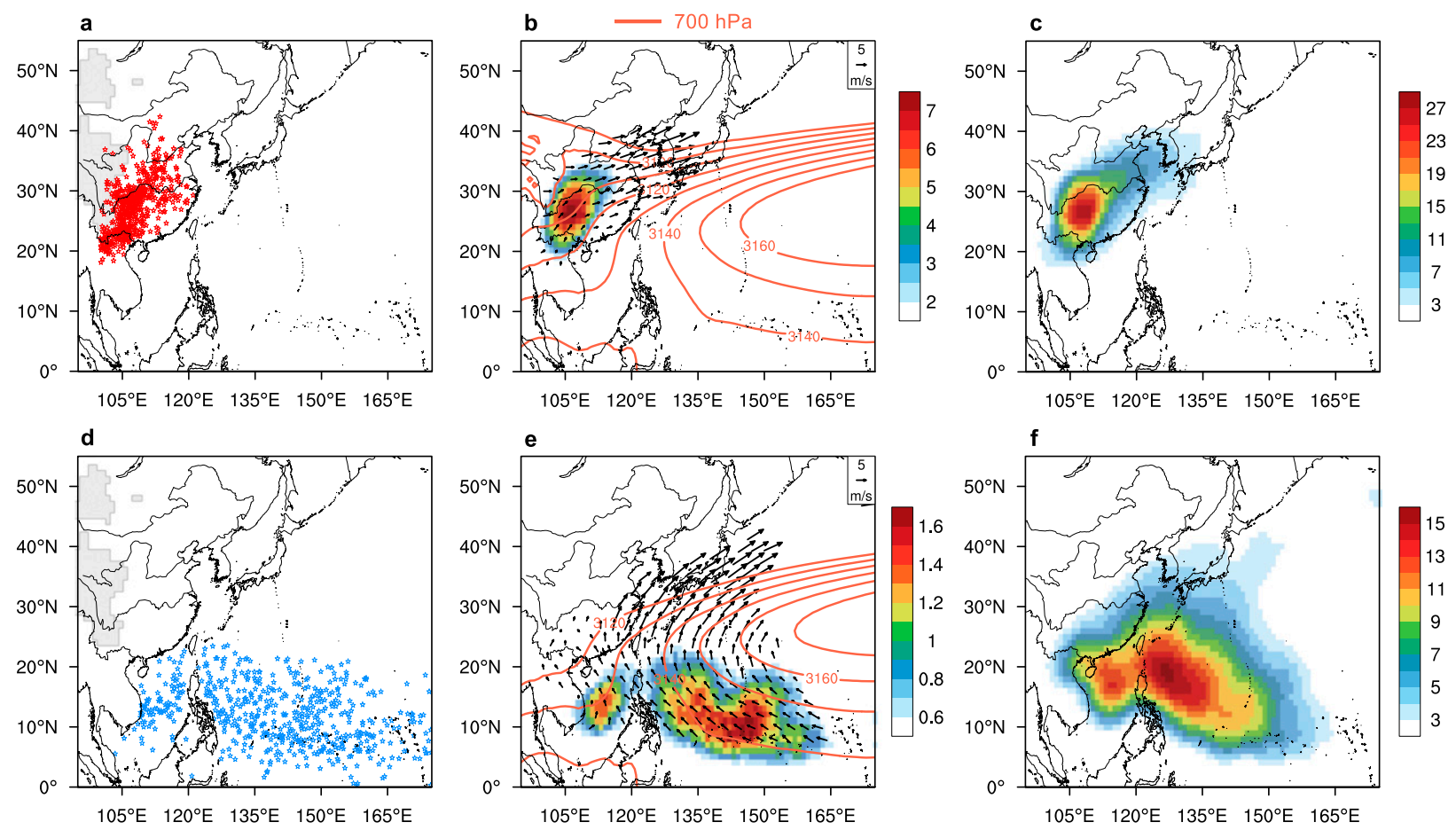

FIG. 2. (a),(d) Genesis locations, (b),(e) climatological genesis density (number of LPSs per summer; shading) and translation vector $\left(\mathrm{m} \mathrm{s}^{-1}\right.$; arrows) overlapped with climatological summer 700-hPa geopotential height ( $\mathrm{m}$; colored contours), and (c),(f) climatological track density (number of LPS days per summer; shading) for the MJJAS (a)-(c) terrestrial LPSs and (d)-(f) marine LPSs during the period 1979-2018. The contour interval in (b) and (e) is $10 \mathrm{~m}$. Regions where the 850-hPa pressure level falls below ground are denoted by black dots and gray shading in (a) and (d).

dipole. The wind anomaly is axially asymmetric with maximum values in the southeast quadrant. In contrast to the cold anomaly, which is confined in a relatively shallow layer, the warm anomaly extends upward to the tropopause and intensifies with height (Fig. 3c). The warm anomaly aloft is likely a response to the diabatic heating induced by the rainfall, which is located in the northeast quadrant and within the warm sector near the leading edge of the front (Figs. 3a,b). In accordance with the upper-tropospheric warm anomaly, the cyclonic circulation weakens with height above $700 \mathrm{hPa}$ and switches into anticyclonic circulation at $400 \mathrm{hPa}$ (Figs. 3c,d). The warm core is reminiscent of tropical-like storms as compared to monsoon depressions formed over the humid Indian subcontinent (e.g., Hurley and Boos 2015; Hunt et al. 2016), indicating the importance of diabatic processes in the genesis and intensification of terrestrial LPSs. However, the lower-tropospheric frontal structure is indicative of the potential role of baroclinic instability as compared to extratropical storms. Thus, the terrestrial LPSs likely belong to a hybrid storm type with both tropical and extratropical characteristics. However, a complete energetic analysis is beyond the scope of the present work and will be examined in future studies.

The structure of the composited marine LPSs is consistent with the classical tropical storms, although the LPSs identified here do not all reach the strength of TCs. The composited structure shows little vertical tilt and is axisymmetric about the vortex center (Figs. 3g,h). While the temperature anomaly is fairly weak in the lower troposphere, it increases sharply with height. At $850 \mathrm{hPa}$, the weak cold anomalies in the cyclone center, which may be attributable to the reduced solar radiation and the evaporative cooling of falling droplets, are surrounded by warm anomalies induced by the weak subsidence outside the core region (Fig. 3e). The most intense upward motion and rainfall are found near the cyclone center (Figs. 3e,f), in which the latent heat release generates a warm core in the upper troposphere (Fig. $3 \mathrm{~g}$ ). Correspondingly, the cyclonic circulation, which is strongest between 900 and $500 \mathrm{hPa}$, gradually weakens with height (Fig. $3 \mathrm{~g}$ ). For both types of LPSs, rainfall patterns similar to those shown in Figs. $3 \mathrm{~b}$ and $3 \mathrm{f}$ are identified in APHRODITE, but only using rainfall data over land grids as APHRODITE data are not available over ocean.

\section{Connections between monsoon LPSs and extreme precipitation}

To quantify the role of monsoon LPSs in extreme rainfall, a method is developed to identify rainfall events that are intimately connected with the LPSs. Although the composited rainfall shown in Figs. $3 \mathrm{~b}$ and $3 \mathrm{f}$ is not completely symmetric about the center, it is largely confined within a certain radius from the cyclone center. Hence, we adopt the widely used 
a

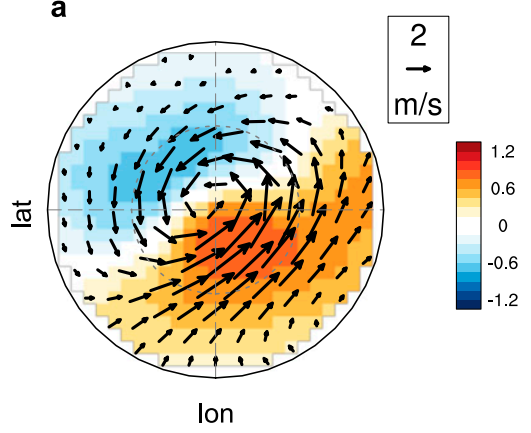

b

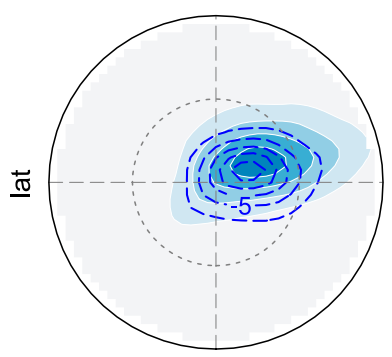

Ion
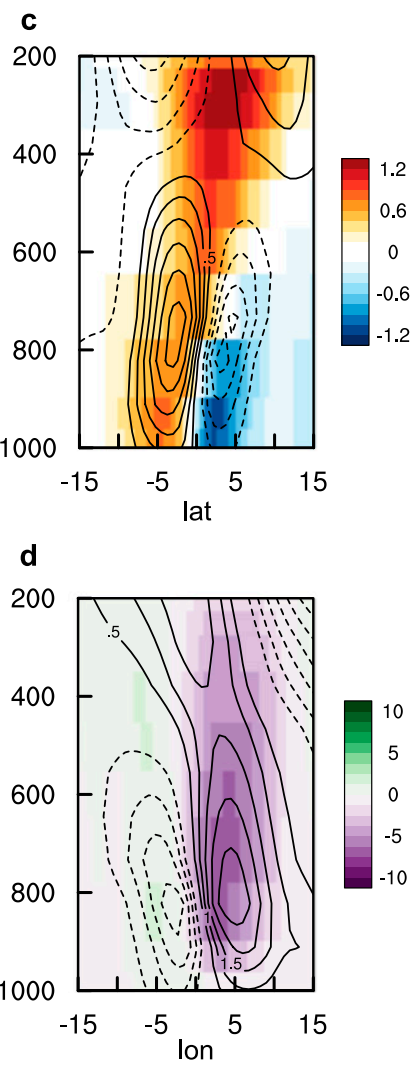

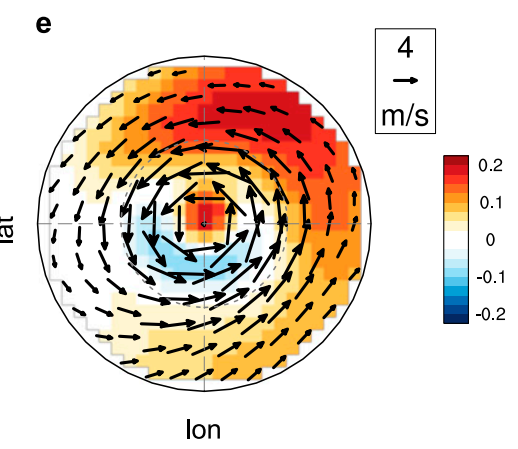

$\mathbf{f}$
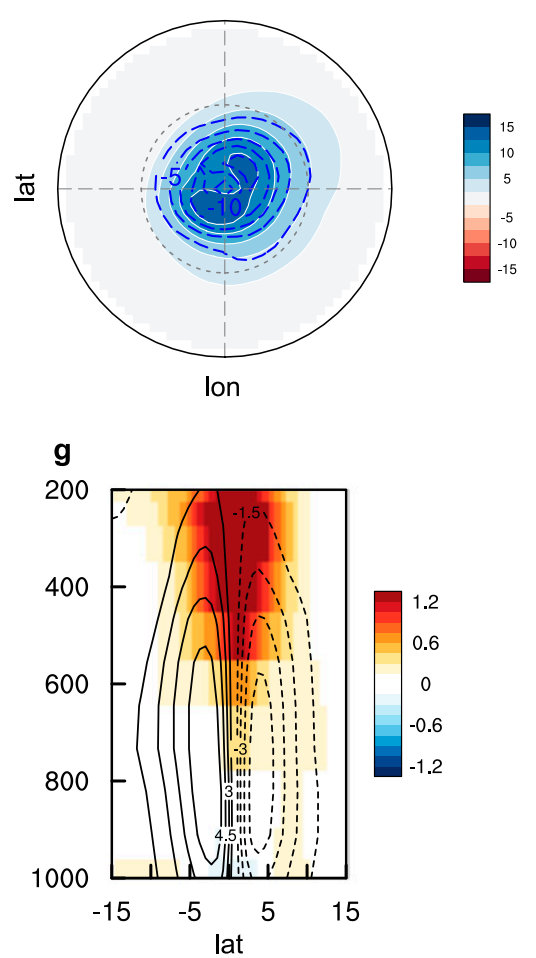

h

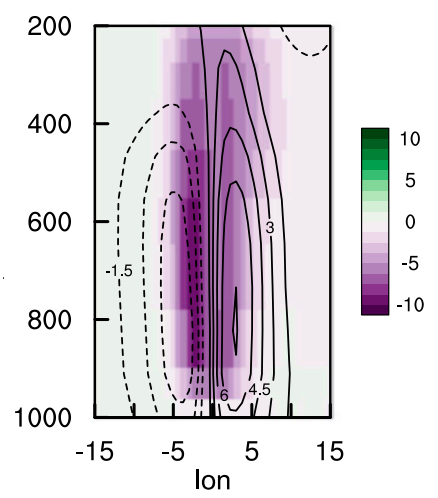

FIG. 3. Terrestrial LPS-centered composites of the ERA-I 850-hPa (a) anomalous potential temperature (K; shading) and horizontal winds ( $\mathrm{m} \mathrm{s}^{-1}$; vectors), (b) anomalous vertical velocity $\left(10^{-2} \mathrm{~Pa} \mathrm{~s}^{-1}\right.$; contour) and rainfall (mm day; shading), (c) latitude-pressure cross section [vertical dashed line in (a)] of temperature (K; shading) and zonal wind ( $\mathrm{m} \mathrm{s}^{-1}$; contour), and (d) longitude-pressure cross section [horizontal dashed line in (a)] of vertical velocity $\left(10^{-2} \mathrm{~Pa} \mathrm{~s}^{-1}\right.$; shading) and meridional wind ( $\mathrm{m} \mathrm{s}^{-1}$; contour). (e)-(h) As in (a)-(d), but for marine LPSs. The inner dashed and outer solid circles in (a), (b), (e), and (f) indicate the $5^{\circ}$ and $10^{\circ}$ radius, respectively. The contour interval is $2.5 \times 10^{-2} \mathrm{~Pa} \mathrm{~s}^{-1}$ in (b) and (f), $0.5 \mathrm{~m} \mathrm{~s}^{-1}$ in (c) and (d), and $1.5 \mathrm{~m} \mathrm{~s}^{-1}$ in (g) and (h) with negative contours dashed and zero contours omitted. 

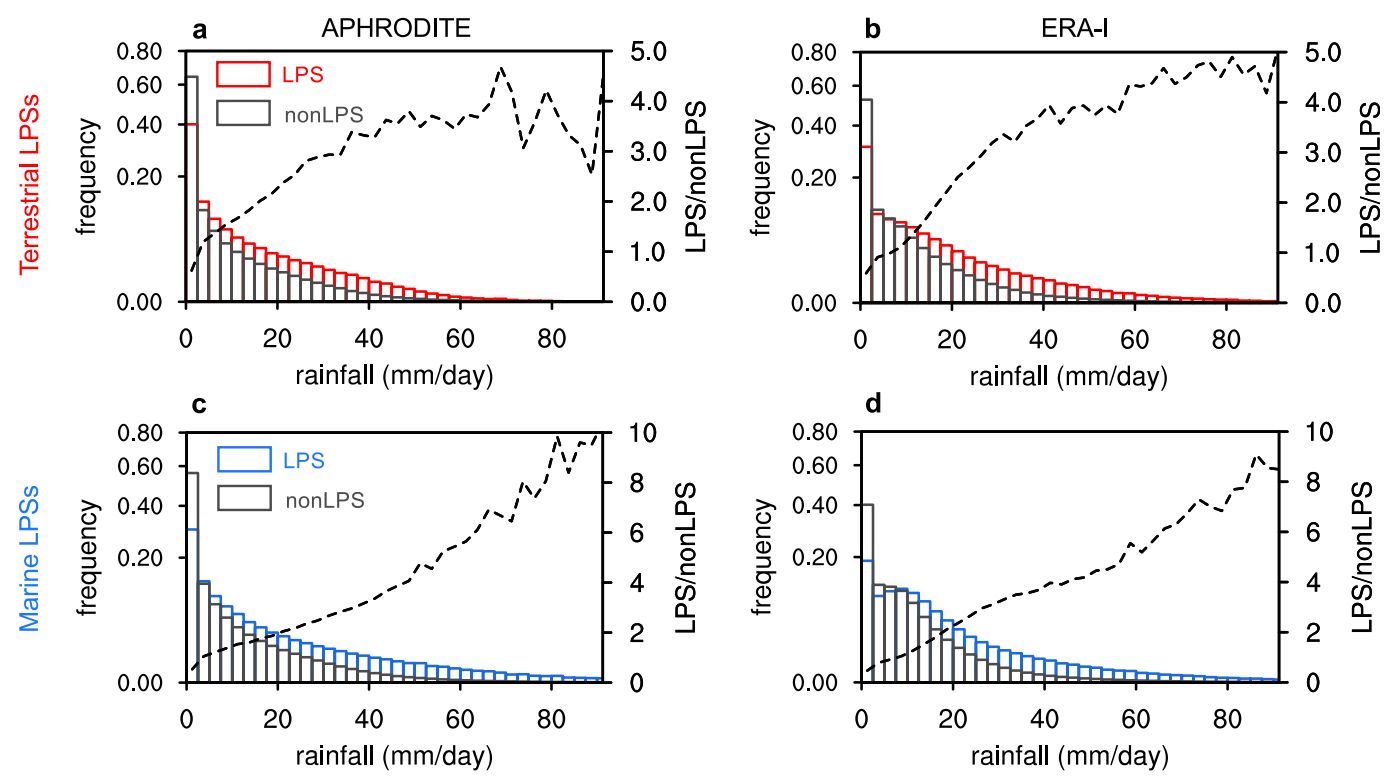

FIG. 4. Normalized histograms for the MJJAS LPS-related (colored histograms) and non-LPS-related (black histograms) daily grid point rainfall for all land grids where the climatological LPS track density is at least 3 LPS days per summer, based on (a),(c) APHRODITE and (b),(d) ERA-I rainfall datasets, for (a),(b) terrestrial LPSs and (c),(d) marine LPSs. The daily rainfall is divided into bins with a uniform width of $2.5 \mathrm{~mm}^{-1} \mathrm{yy}^{-1}$, where 0 indicates $0-2.5 \mathrm{~mm} \mathrm{day}^{-1}, 20$ represents $20-22.5 \mathrm{~mm} \mathrm{day}^{-1}$, and so forth. Note that the left-hand vertical axis is scaled as the square root of frequency to accommodate the zero-inflated and heavy-tailed distribution. The ratio of the LPS-related rainfall frequency vs the non-LPS-related rainfall frequency is shown as black dashed lines using the right (linear) axis. The total number of $0.5^{\circ} \times 0.5^{\circ}$ land grid points included is 1345 in (a) and(b) and 1108 in (c) and (d).

fixed-radius approach, in which the rainfall is considered to be LPS-induced when it falls within a predefined radius from the LPS center (e.g., Jiang and Zipser 2010; Pfahl and Wernli 2012; Hurley and Boos 2015; Zhang et al. 2018). In the present study, the effective radius of LPS is set to $500 \mathrm{~km}$ considering the typical radius of LPS circulation and the spatial extent of LPSrelated rainfall. We define daily precipitation events to be LPSinduced if they fall within $500 \mathrm{~km}$ of the LPS center in a time window of \pm 1 day. The time window of \pm 1 day is chosen to accommodate the potential underestimation caused by the use of daily rainfall data as the precipitation induced by a single cyclone may occur within a consecutive time window and run across midnight from one day to the next (e.g., Knight and Davis 2009; Pfahl and Wernli 2012; Khouakhi et al. 2017; Zhang et al. 2018). Additionally, different stations measure precipitation within different 24-h time intervals (Yatagai et al. 2012). Our main conclusions are insensitive to reasonable changes in radius (such as 400 to $700 \mathrm{~km}$; not shown).

Using the fixed-radius approach, the monsoon LPS-related daily rainfall is tracked along individual trajectories. To avoid double-counting, once a daily rainfall record is attributed to one specific LPS, the record is removed from further counting for any additional LPSs. This approach classifies daily rainfall records at each grid point into one LPS-related component and one residual component containing the rest. The LPS- and nonLPS-related daily rainfall characteristics are compared in the form of normalized histograms at every land grid point where the climatological track density is at least three LPS days per summer (Figs. 2c,f and 4). The mean 90th percentile of daily rainfall at these land grid points is about $15 \mathrm{~mm} \mathrm{day}^{-1}$ with some spatial variations across the domain. As shown in Fig. 4, the LPS-related rainfall exhibits a clear shift in the distribution of rainfall intensity compared to the non-LPS-related rainfall and has a longer tail toward heavier amounts. The two distributions are statistically distinguishable from each other as suggested by the nonparametric Kolmogorov-Smirnov significance test. In the presence of terrestrial (marine) LPSs, the probabilities for heavier rainfall to take place are up to 5 (10) times as much compared to those in the absence of LPSs (black dashed lines in Fig. 4). The stronger association between marine LPSs and heavy terrestrial rainfall is probably owing to the coastally confined track density (Fig. 2) and the more powerful cyclone intensity (Fig. 3). Note that although the occurrence of near-zero rainfall events (i.e., $<2.5 \mathrm{~mm} \mathrm{day}^{-1}$ ) is substantially lower in LPS-related rainfall than that in the non-LPS-related component, a relatively large amount of LPS days are still connected with nearzero rainfall events. In other words, not all land grid points within the $500-\mathrm{km}$ radius of LPSs contain heavy rainfall. The excessive occurrence of near-zero LPS-related rainfall may be attributable to either the weak rainfall grids located outside the LPSs' major rainband but within the $500-\mathrm{km}$ radius of the LPS center, or the weak storm intensity during the early and late stages of the LPSs' life cycle. 
Terrestrial LPSs
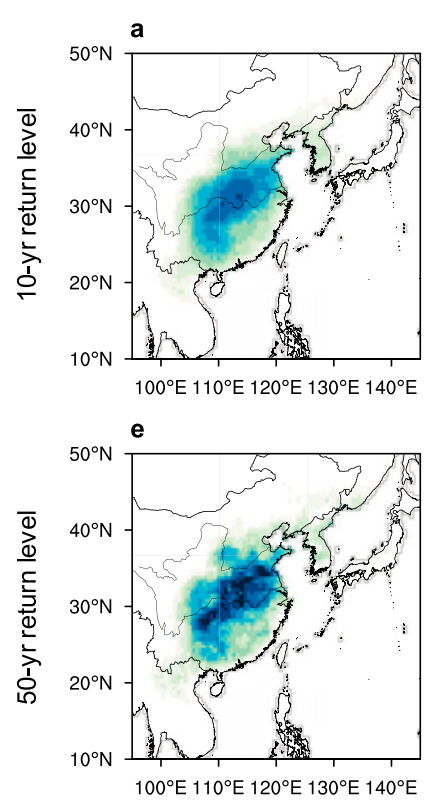
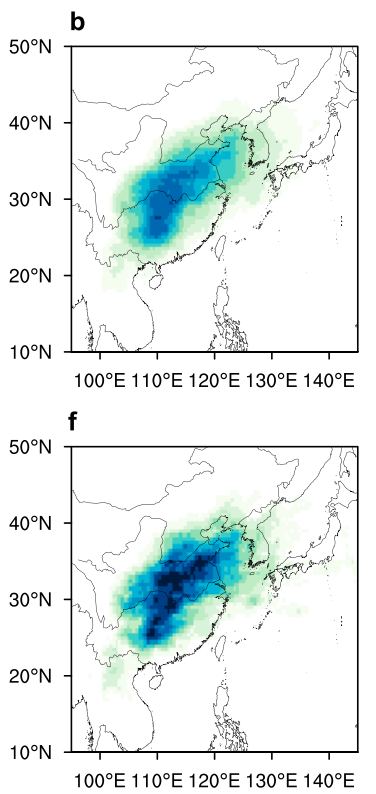

Marine LPSs
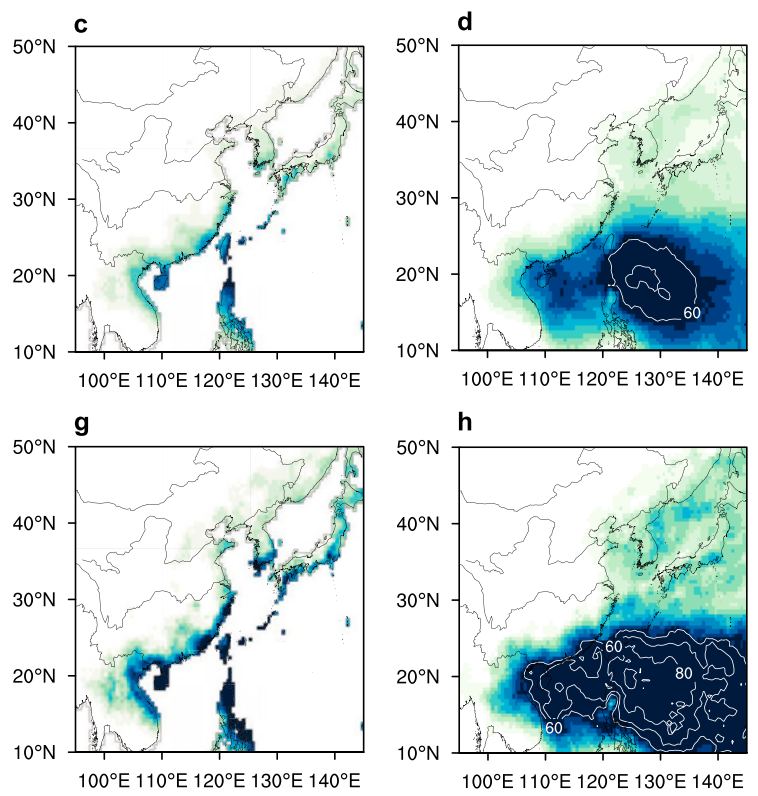

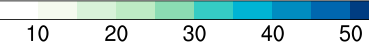

FIG. 5. Fractional contribution (\%; shading) of (a),(b),(e),(f) terrestrial and (c),(d),(g),(h) marine LPSs to the extreme precipitation exceeding the (a)-(d) 10- and (e)-(h) 50-yr return periods in (a),(c),(e),(g) APHRODITE and (b),(d),(f),(h) ERA-I datasets. The white contours in (d) and (h) start from $60 \%$. Contour interval is $10 \%$.

In the following analyses we focus on heavy rainfall events, for which the presence of LPSs makes a big difference. At each grid point, the extreme precipitation is defined as daily rainfall exceeding the 10- and 50-yr return period, which is represented by the 90th and 98th percentiles of the summertime daily precipitation, respectively (i.e., the peak-over-threshold method). The contribution of monsoon LPSs to extreme precipitation at each grid point is measured by the ratio of the LPS-related extreme precipitation amount to the total extreme precipitation amount. The contributions of LPSs to the summer extreme rainfall are depicted in Fig. 5 for both the ERA-I and AHRODITE rainfall datasets. For daily rainfall exceedances of the $10-\mathrm{yr}(50-\mathrm{yr})$ return period, the maximum fractional contribution of terrestrial and marine LPSs reaches $50.6 \%(63.2 \%)$ and $60.4 \%(80.6 \%)$ over land grids, respectively. The rainfall extremes exceeding the 50 -yr return period, in general, have a higher contribution from the LPSs than those exceeding the 10-yr return period, suggesting that the more intense rainfall is more likely to be initiated by LPSs (Figs. 5a-d vs Figs. 5e-h). In agreement with the relative location of rainfall to the terrestrial LPS center (Fig. 3), the areas having the greatest fractional contribution from terrestrial LPSs are displaced slightly eastward, as compared to the track density shown in Fig. 2c. In contrast to the terrestrial LPSs, which primarily influence the extreme rainfall over the densely populated inland areas (i.e., middle and lower reaches of the Yangtze and Yellow Rivers), the fractional contribution of marine LPSs diminishes rapidly landward (e.g., Pfahl and Wernli 2012; Khouakhi et al. 2017). The marine LPSs predominantly impact the extreme rainfall over the WNP and SCS, as well as a narrow stretch of coastal regions, such as the southern and southeastern China coasts, Hainan and Taiwan Islands, the northern Indochina Peninsula, and the Philippines (Figs. 5b,d,f,h).

We further examine the long-term trends in LPS track density and LPS-related rainfall extremes. At each grid point, the LPS-related daily rainfall is summed over each summer to produce yearly time series. Owing to the relatively small sample size of precipitation exceeding the 50-yr return level, only results based on the 10 -yr return level are presented in the following analyses. The trend is computed as linear regression to time at each grid point and the significance is tested using a two-tailed nonparametric Mann-Kendall method (Mann 1945). The trends of the terrestrial LPS track density and associated rainfall extremes are characterized by an oppositesigned dipole pattern. The positive center of the track density trend is located in the region where the majority of terrestrial LPSs formed, whereas the negative center resides near the endpoint of the terrestrial LPS tracks (Figs. 6a,d). The corresponding extreme rainfall dipole is more pronounced in the ERA-I than the APHRODITE (Fig. 6d), possibly owing to a higher physical consistency between reanalysis-derived LPSs and rainfall. With regard to the marine LPSs, the track density decreases to the south and increases to the north of the climatological track density maxima (Figs. 6b,e). As a consequence, the marine LPS-related extreme rainfall exhibits an increasing trend in the eastern China coast and a decreasing trend in the SCS. The trends are verified by comparing the epochal differences in the early and late halves of the $40-\mathrm{yr}$ 

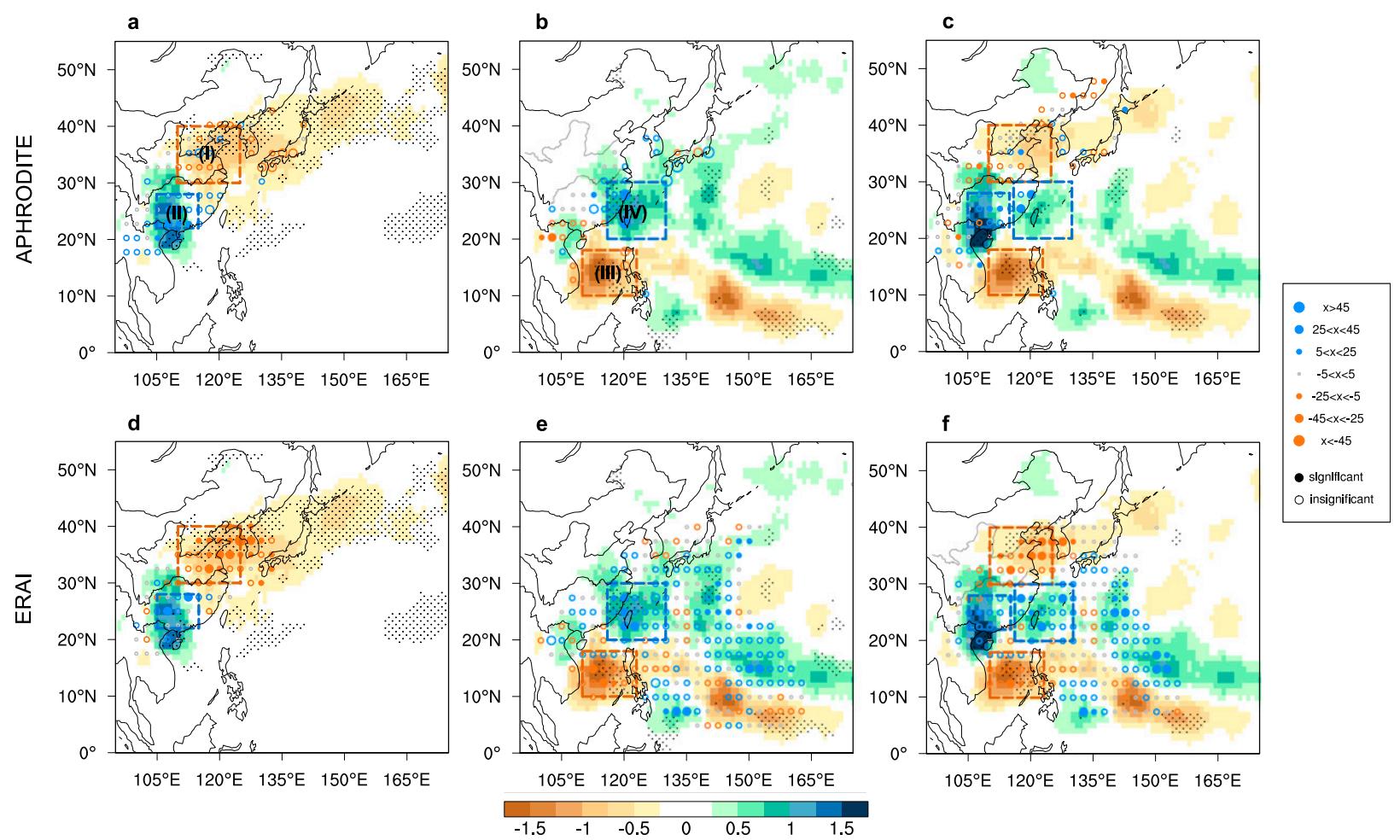

FIG. 6. Linear trend of the MJJAS (a),(d) terrestrial LPS, (b),(e) marine LPS, and (c),(f) all LPS track density (number of LPS days per decade; shading) and LPS-related extreme precipitation ( $\mathrm{mm} \mathrm{decade}^{-1}$; dots). (a)-(c) APHRODITE and (d)-(f) ERA-I rainfall. Rainfall extremes are defined as exceedances above the 10-yr return level. The linear trends are shown only in those regions where the climatological track density is at least 3 days per summer. The dashed boxes labeled I-IV represent areas used for averaging in Figs. 7 and 8. Significance of the linear trends is evaluated using a nonparametric Mann-Kendall test at $90 \%$ confidence level.

data (i.e., 1979-98 vs 1999-2018; not shown). While there are some cancellations between the terrestrial LPS-induced and the marine LPS-induced extreme rainfall trends, the overall pattern when considering both tend to agree with the "south flood-north drought" pattern (Figs. 1a,b and Figs. 6c,f) with a gross increasing trend in southern China (regions II and IV) and a decreasing trend in the north-central China (region I), as previously identified in observations (e.g., Liu et al. 2005; Dong et al. 2011).

To what extent could the total extreme rainfall trends be explained by those related to LPSs? Figure 7 presents the yearly time series of the total, LPS-related, and non-LPSrelated ERA-I extreme rainfall amounts averaged over the four main subregions shown in Figs. 6a and 6b. We also examined the corresponding results using APHRODITE, but the lack of rainfall data over the ocean grids makes it less ideal for this purpose. In all four regions, the total extreme rainfall exhibits significant trends. While the LPSs only account for roughly $45 \%$ of the rainfall extremes exceeding the 10 -yr return period in northern China and eastern China coasts (regions I and IV in Figs. 6a,b), the LPS-related extreme rainfall explains nearly all of the trend signal (Figs. 7a,d). On the contrary, although the LPSs make a sizable contribution to total extreme rainfall amounts in the southwestern inland area and northern SCS (regions II and III in Figs. 6a,b), the LPS alone is insufficient to fully account for the trend (Figs. 7b,c). A plausible reason is that southwestern China and northern SCS are located near the convergence zone of monsoonal southwesterlies and easterly trades (i.e., monsoon trough; Figs. $2 \mathrm{~b}, \mathrm{e})$, where the extreme rainfall variability could also be modulated by tropical intraseasonal oscillations and variations in larger-scale circulation.

\section{Mechanisms driving the LPS track density trend}

Changes in LPS rainfall in a given region can be caused by either changes in LPS occurrence or changes in LPS rainfall intensity, or both. While thermodynamic moistening can be of critical importance in future warming scenario (e.g., Emori and Brown 2005; Held and Soden 2006; O'Gorman and Schneider 2009; Pfahl et al. 2017), the close alignment between the spatial patterns of LPS track density and LPS-related extreme precipitation trends emphasizes the predominance of LPS occurrence in modulating the regional extreme rainfall trends (Figs. 6 and 7).

To determine whether trends in the LPS track density are due to changes in genesis or propagation, the statistical attribution technique introduced in section $2 \mathrm{c}$ is applied to the 

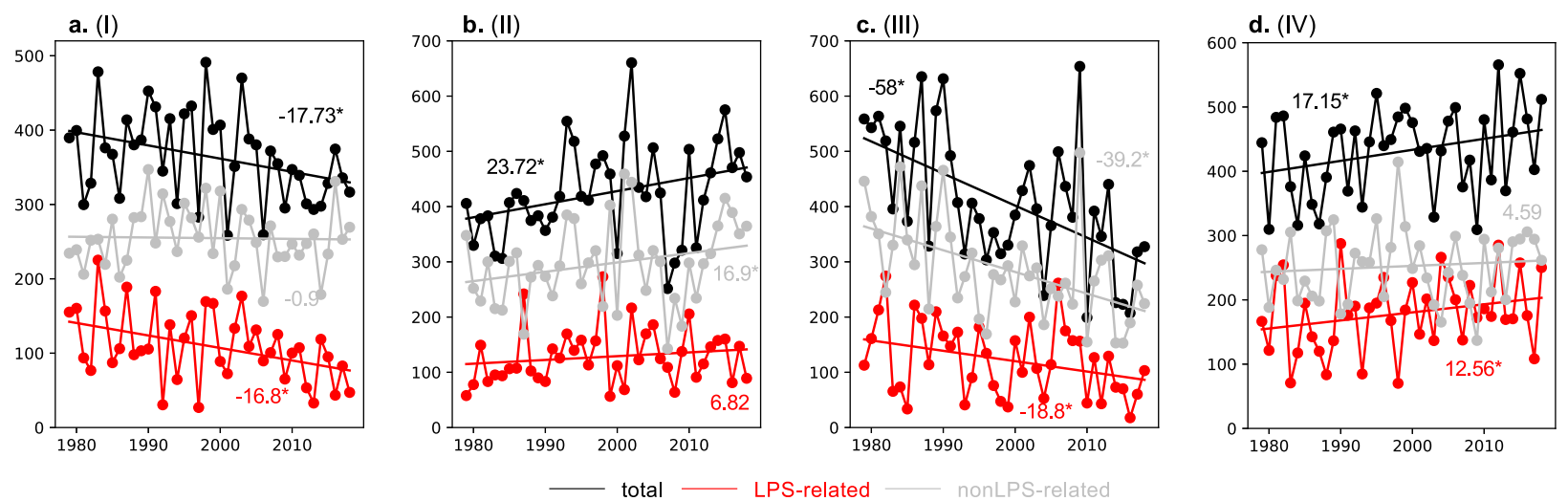

FIG. 7. Time series of ERA-I extreme rainfall amount (black line), LPS-related extreme rainfall amount (red line), and non-LPS-related extreme rainfall amount (gray line) in (a) region I: northern China $\left(30^{\circ}-40^{\circ} \mathrm{N}, 110^{\circ}-125^{\circ} \mathrm{E}\right)$; (b) region II: southern $\mathrm{China}^{\circ}\left(22^{\circ}-28^{\circ} \mathrm{E}, 105^{\circ}-\right.$ $\left.115^{\circ} \mathrm{E}\right)$; (c) region III: northern SCS $\left(10^{\circ}-17^{\circ} \mathrm{N}, 110^{\circ}-123^{\circ} \mathrm{E}\right)$; and (d) region IV: eastern China coasts $\left(20^{\circ}-30^{\circ} \mathrm{N}, 115^{\circ}-130^{\circ} \mathrm{E}\right)$. Regions I-IV are boxed in Fig. 6 . The values of the linear trends $\left(\mathrm{mm} \mathrm{decade}^{-1}\right)$ are shown in each panel. An asterisk indicates greater than $90 \%$ significance. Rainfall extremes are defined as exceedances above the 10 -yr return level.

epochal differences in track density between 1999-2018 and 1979-98. For each of the four boxed regions shown in Fig. 6 , the attribution technique [Eq. (2)] decomposes the epochal changes in track density into those due to changes in propagation $\left[\iint g\left(A_{0}\right) \Delta t\left(A \mid A_{0}\right) d A_{0}\right]$ and those due to changes in genesis $\left[\iint \Delta g\left(A_{0}\right) t\left(A \mid A_{0}\right) d A_{0}\right]$. To ease comparison between fields of different magnitudes, for each region the contributions of propagation and genesis are normalized by the changes in track density [i.e., the single term on the left-hand side of Eq. (2), $\Delta f(A)]$ to obtain the normalized contributions. For terrestrial LPSs, the change in propagation accounts for $146 \%$ and $83 \%$ of the track density changes in regions I and II, respectively, which far outweighs the contribution due to changes in genesis $(-44 \%$ and $12 \%$; Fig. $8 \mathrm{a})$. With regard to the spatial pattern, the changes due to propagation are of the same sign across the entire domain as compared to changes in track density. In region I, the changes in track density and that due to propagation are both negative, indicating that fewer terrestrial LPSs migrate through this region in the later epoch (Fig. 8b). On the contrary, in region II the positive change in track density and that due to propagation suggest that the terrestrial LPSs spend more of their lifetime in this region (Fig. 8c). Because the majority of terrestrial LPSs form in region II (Fig. 2a), this implies that the terrestrial LPSs travel a shorter distance and prefer to stay in their source region in the later epoch.

For marine LPSs, the technique is applied to the two offshore regions with the most significant track density trends (regions III and IV in Fig. 6b). In both regions, the changes in track density are overwhelmed by the changes in propagation (114\% and $74 \%$; Fig. 8 a), which exhibit pronounced differences extending westward from the Philippine Sea (Figs. 8d,e). The negative track density trend in region III results from a declining number of the westward-moving LPSs that pass through the Philippines and propagate into the SCS (Fig. 8d), while the positive trend in region IV is induced by an increasing number of the northward-recurving LPSs that veer toward the East Asian coasts over the Philippine Sea (Fig. 8e). Although the positive track density trend near $25^{\circ} \mathrm{N}, 140^{\circ} \mathrm{E}$ is not statistically significant (Figs. 6b,d), the trend pattern as a whole indicates a poleward shift of marine LPS trajectories toward the end of the study period, consistent with previous observational and modeling studies on WNP TCs (e.g., Tu et al. 2009; Knutson et al. 2010; Chang et al. 2012; Chu et al. 2012; Kossin et al. 2014, 2016; Liang et al. 2017; Zhang et al. 2018).

The attribution technique emphasizes that changes in propagation play a decisive role in determining the track density trend. The translation direction and speed of LPSs are, to a large extent, governed by the environmental steering flow as seen by the close parallels between the translation vectors and the climatological 700-hPa geopotential height contours (Fig. 2). To investigate how the epochal changes in LPS tracks are driven by changes in large-scale circulation, we first show in Fig. 9 the environmental steering associated with certain types of LPS trajectories. The steering is obtained by compositing the daily $700-\mathrm{hPa}$ geopotential height over all the days when a specific type of LPS trajectories is active. To incorporate the possible influences from the variabilities beyond synoptic time scale, we composite anomaly fields, which are calculated as departures from the full 40-yr daily climatology. For terrestrial LPSs, of which the translation direction is relatively monotonic and points toward the northeast (Fig. 2c), all the days when the terrestrial LPSs stay over land are included in the composite. Compared to the climatological steering, during the days when the terrestrial LPSs are active, in the lower troposphere a stronger-than-normal high pressure appears in the vicinity of Taiwan Island and to the south of the terrestrial LPS propagation pathway. The anomalously strong southwesterlies steer terrestrial LPSs out of the cyclogenesis region (Fig. 9a). For marine LPSs, composites are conducted separately for the westward-moving LPSs passing through the SCS (region III) and the northwardrecurving LPSs passing through the eastern China coast (region IV). The westward-moving marine LPSs are inhibited from veering northward by the anomalously high pressure 


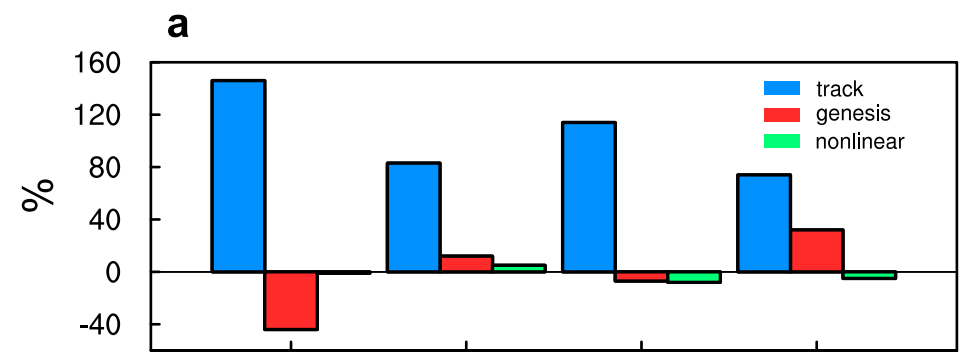

(I)

(II)

(III)

(IV)
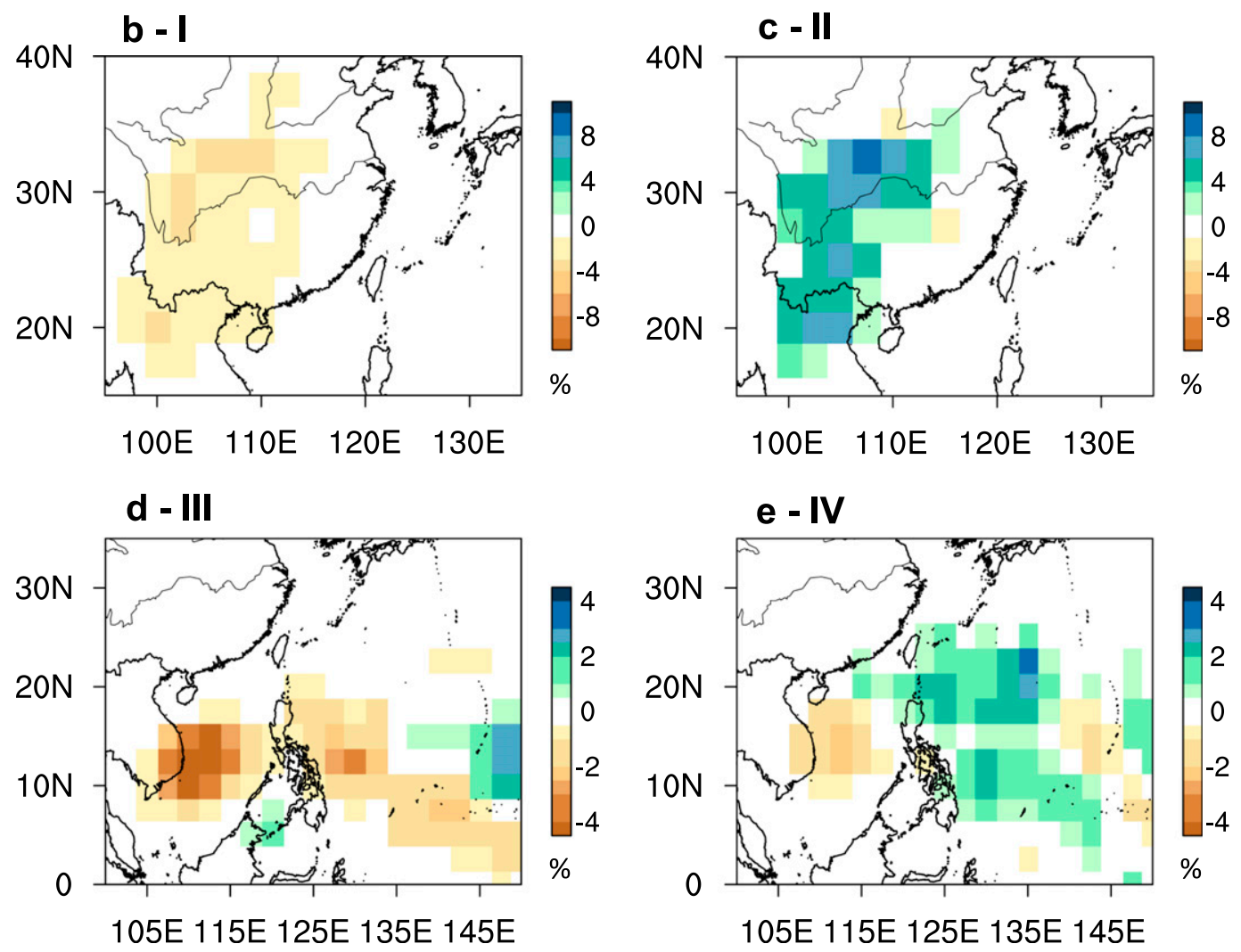

FIG. 8. (a) Normalized contribution (\%) of propagation term $g\left(A_{0}\right) \Delta t\left(A \mid A_{0}\right)$, genesis term $\Delta g\left(A_{0}\right) t\left(A \mid A_{0}\right)$, and nonlinear term $\Delta g\left(A_{0}\right) \Delta t\left(A \mid A_{0}\right)$ to the epochal change in track density $(\Delta f(A) ; A$ corresponds to the four regions boxed in Fig. 6) between the periods 1999-2018 and 1979-98 in the four regions outlined in Fig. 6. (b)-(e) Spatial pattern of the normalized [by the absolute value of $\Delta f(A)$ ] propagation term $g\left(A_{0}\right) \Delta t\left(A \mid A_{0}\right)$ before the spatial integration-(b) region I: northern China $\left(30^{\circ}-40^{\circ} \mathrm{N}, 110^{\circ}-125^{\circ} \mathrm{E}\right)$; (c) region II: southern China $\left(22^{\circ}-28^{\circ} \mathrm{E}, 105^{\circ}-\right.$ $\left.115^{\circ} \mathrm{E}\right)$; (d) region III: northern SCS $\left(10^{\circ}-17^{\circ} \mathrm{N}, 110^{\circ}-123^{\circ} \mathrm{E}\right)$; and (e) region IV: eastern China coasts $\left(20^{\circ}-30^{\circ} \mathrm{N}\right.$, $\left.115^{\circ}-130^{\circ} \mathrm{E}\right)$.

centered over eastern China and are steered toward the SCS by the strong easterlies to their north (Fig. 9b). Contrastingly, the marine LPSs that recurve toward higher latitudes before they reach the Philippines are closely associated with the low pressure anomalies centered over Taiwan Island and the high pressure anomalies positioned to the east of Japan (Fig. 9c). As most of the marine LPSs form in the tropical easterlies and move along the periphery of the WNP subtropical high, the composites indicate that the marine LPS trajectories are largely modulated by the westward and northward extent of the subtropical high.

Given the close association between the shifts of LPS tracks and the changes in large-scale steering, we now explore the mechanisms driving the epochal changes in LPS track density by examining the epochal difference in the summer mean environmental steering between 1999-2018 and 1979-98 (Fig. 9d). One of the most prominent features is the positive geopotential height anomaly on the poleward flank of the 
a Terrestrial LPSs
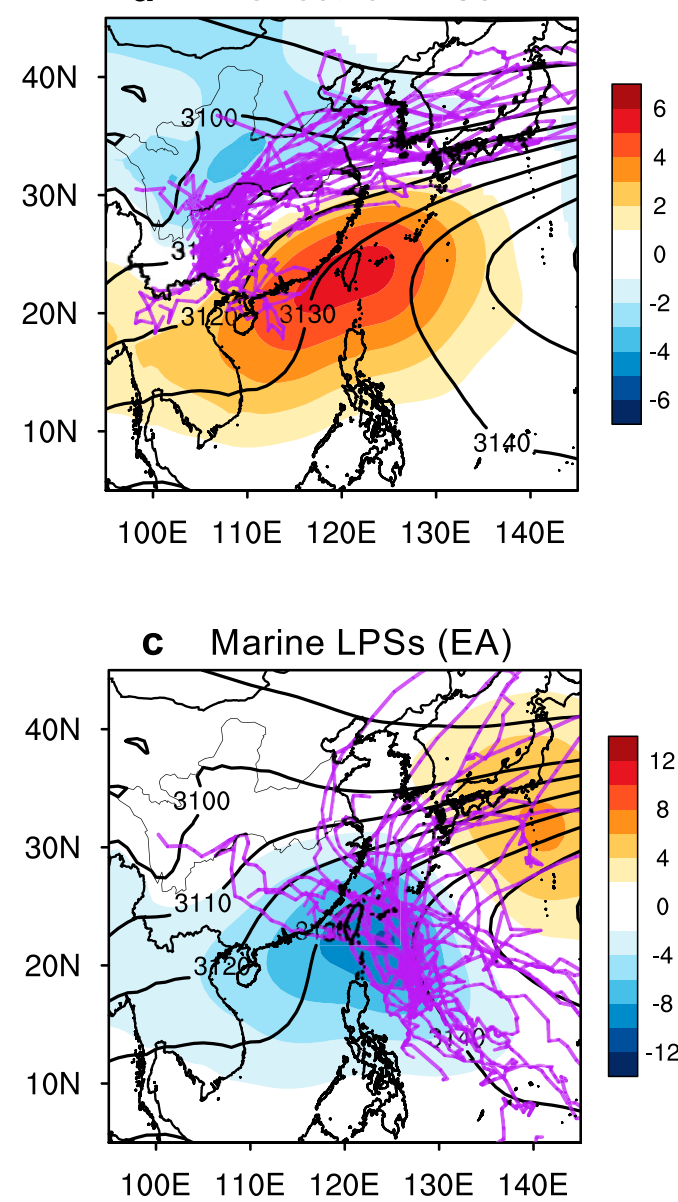
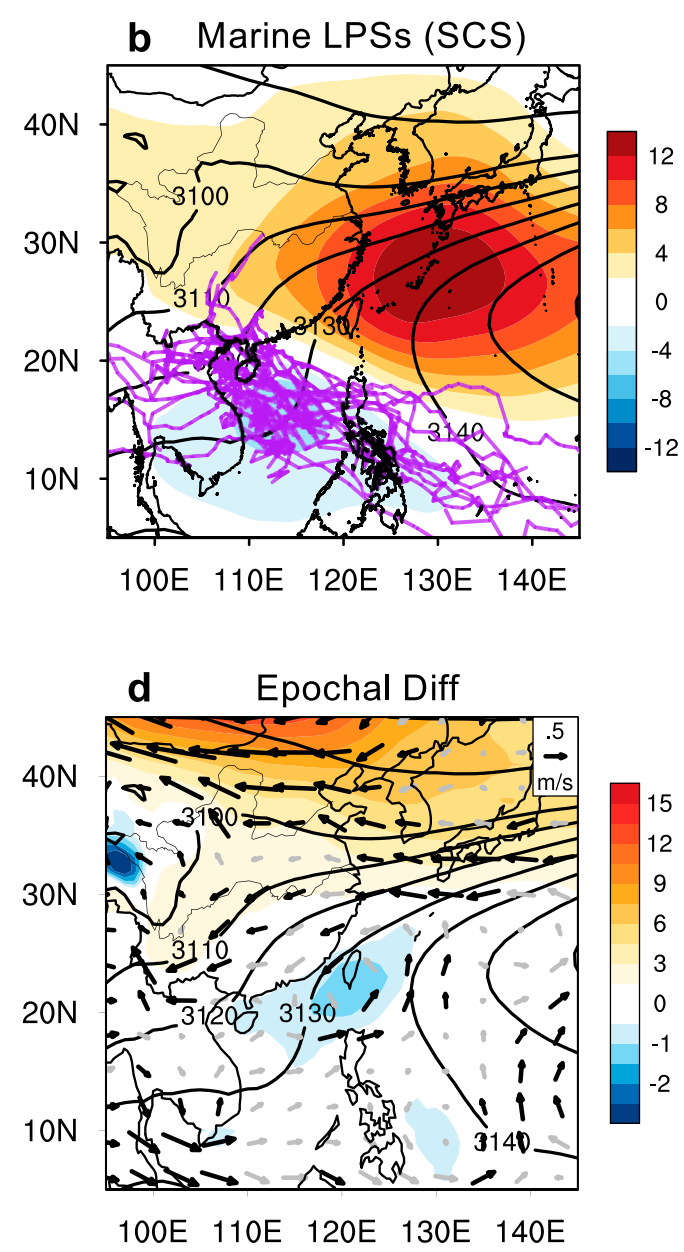

FIG. 9. Composites of anomalous daily 700-hPa geopotential height (m; shading) for (a) terrestrial LPSs, (b) marine LPS passing through northern SCS (region III in Fig. 6b), and (c) marine LPSs passing through the eastern China coast (region IV in Fig. 6b). Only significant values are drawn. Trajectories superimposed (purple lines) are randomly chosen from all the trajectories included in the composites. (d) Epochal difference (1999-2018 minus 1979-98) of MJJAS mean 700-hPa geopotential height ( $\mathrm{m}$; shading) and wind ( $\mathrm{m} \mathrm{s}^{-1}$; vector). Black contours in (d) represent the climatological summer 700-hPa geopotential height (m). Wind vectors above (below) the $90 \%$ confidence level are shown in black (gray) vectors.

subtropical high, which reduces the meridional gradient of geopotential height and produces anomalous northeasterlies. The anomalous northeasterlies are unfavorable for the propagation of terrestrial LPSs, thus leading to the track density dipole of terrestrial LPSs as identified in Fig. 6a. Besides the pronounced anomalies in high latitudes, a statistically significant cyclonic anomaly appears in the southeastern China coast, albeit with less prominent amplitude. The cyclonic anomaly, which implies an eastward retreat of the WNP subtropical high, not only reduces the southwesterly steering for the terrestrial LPSs but also promotes the northward recurvature of marine LPSs.

\section{Summary and discussion}

Using the ERA-I dataset, which spans the period 1979-2018, we have investigated the characteristics of monsoon LPSs over the Southeast and East Asian summer monsoon regions and have quantified their contributions to the long-term trend of rainfall extremes. Here the monsoon LPSs were tracked using an objective feature-tracking algorithm and a post-tracking filter. Results show that cyclogenesis is particularly active over this region and the genesis locations exhibit a clear land-sea separation (Fig. 2). The terrestrial LPSs typically form over the downwind side of the Tibetan Plateau and tend to migrate northeastward toward the jet latitudes. The marine LPSs mainly form over the tropical WNP ocean and South China Sea and propagate along the southern and western periphery of the subtropical high. Pronounced differences were observed between the structures of the terrestrial and marine LPSs (Fig. 3). The marine LPSs correspond well with tropical storms with an axisymmetric structure and a significant upper-tropospheric warm core. In contrast, the terrestrial LPSs possess the attributes 
of both tropical and extratropical storms. The hybrid structure is characterized by a warm core in the upper troposphere and a frontal gradient of temperature and humidity in the lower troposphere.

Both types of LPSs are intensely precipitating. The probability of extreme rainfall occurring during LPSs days is more than twice as high as that during non-LPS days (Fig. 4). The maximum fractional contributions of terrestrial LPSs to the 10and 50-yr return period extreme precipitation reach $50.6 \%$ and $60.4 \%$ over land. This contribution is lower compared to that of the marine LPSs, which reaches $63.2 \%$ and $80.6 \%$, respectively (Fig. 5). However, even though the strength of terrestrial LPSs is overall weaker than that of the marine LPSs, the terrestrial LPSs exert a spatially widespread impact over the densely populated inland areas in southwestern and north-central China. In contrast, the marine LPSs predominantly influence the precipitation over the tropical WNP ocean, and their impacts decline sharply toward inland from the coasts where they frequently make landfall.

During the study period, the track density of terrestrial and marine LPSs exhibits statistically significant trends (Fig. 6). Moreover, the changes in track density are predominantly controlled by changes in LPS propagation (Fig. 8). Toward the end of the study period, more terrestrial LPSs tend to stay in the source region over the southwestern China without significant propagation into north-central China, and more marine LPSs tend to veer northward into the eastern China coasts. These changes are synchronous and spatially coherent with the observed extreme rainfall trend characterized by the "south flood-north drought" dipole pattern (Figs. 1a,b), indicating that extreme rainfall trends are at least partly driven by the LPSs track changes (Fig. 7). The changes in LPS propagation are dynamically modulated by the changes in ambient largescale atmospheric circulation. The more stationary behavior of the terrestrial LPS is caused by the weakened southwesterly steering flow over East Asia, which is largely associated with the elevated geopotential height to the north of the subtropical jet. The poleward migration of marine LPS trajectories is induced by the negative geopotential anomaly near the eastern China coast, which indicates an eastward recess and a weakening of the WNP subtropical high (Fig. 9).

A natural question following is whether the epochal difference is part of the emerging anthropogenic forcing signals or is merely related to the inherent decadal variabilities. We note that the geopotential differences in mid- to high latitudes are not uniform and display a robust wave train-like pattern featuring pronounced positive centers in eastern Europe, Mongolia, and the North Pacific (Fig. 10a). On the other hand, the change in geopotential height generally follows that of temperature, which shows a robust warming pattern in the high northern latitudes (Fig. 10b). The epochal difference, therefore, might not be entirely generated by internal variability but may include a substantial component from anthropogenic warming. In fact, a similar warming pattern has been recognized in several recent studies (e.g., Cohen et al. 2012; Ito et al. 2013; Horton et al. 2015; Sato and Nakamura 2019). For example, Sato and Nakamura (2019) utilized ensemble simulations and found that the pattern consists of a spatially uniform
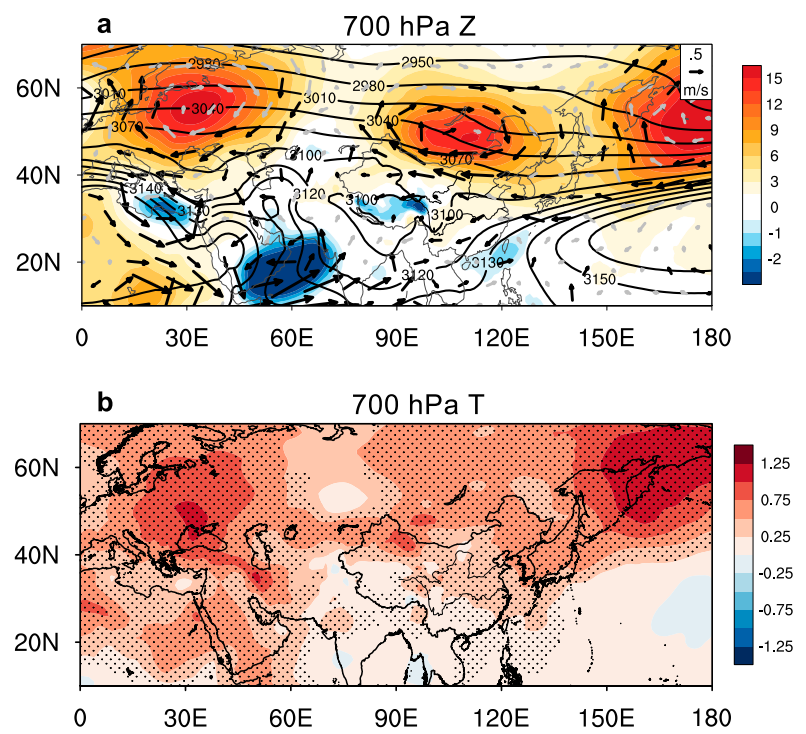

FIG. 10. Epochal differences (1999-2018 minus 1979-98) of the MJJAS mean (a) 700-hPa geopotential height (m; shading) and winds ( $\mathrm{m} \mathrm{s}^{-1}$; vector), overlapped with climatological summer 700hPa geopotential height (m; colored contours), and (b) 700-hPa air temperature $\left({ }^{\circ} \mathrm{C}\right.$; shading). Wind vectors above the $90 \%$ confidence level are shown in black arrows in (a). Stippling in (b) indicates temperature difference exceeding $90 \%$ statistical significance according to a two-tailed Student's $t$ test.

component due to greenhouse gas forcing and a wave train component involving the internal atmosphere-land coupling due to snow cover anomalies. As for the WNP subtropical high, although it has been argued that the WNP subtropical high tends to weaken and retreat eastward in response to global warming (e.g., He et al. 2015), its strength and location are also regulated by the tropical Pacific sea surface temperature anomalies associated with El Niño-Southern Oscillation and Pacific decadal oscillation (PDO). Since the epochal changes in the marine LPS trajectories and the WNP subtropical high in our study period concurred with the PDO phase transition in the late 1990s, after which the positive phase of PDO promotes the formation of a cyclonic anomaly in the WNP (Sharmila and Walsh 2018; Yang et al. 2018), it is possible that the eastward retreat of the WNP subtropical high combines the anthropogenically forced signals and naturally occurring variabilities. Using observations and model outputs, Kossin et al. (2014, 2016) suggested that a substantial portion of the northward migration of tropical cyclones occurs independently of the PDO and is possibly anthropogenically forced. As it is difficult to attribute the trends based on 40 years of observations, future research using climate model simulations is needed.

In addition to the above results that focus on seasonal mean characteristics, the LPSs also exhibit a marked seasonality in accordance with the seasonal march of the East Asian summer monsoon. Figure 11 presents the percentage of terrestrial and marine LPSs formed, the movement of LPSs, and their contributions to total extreme rainfall in each of the summer months. The terrestrial LPSs are most 

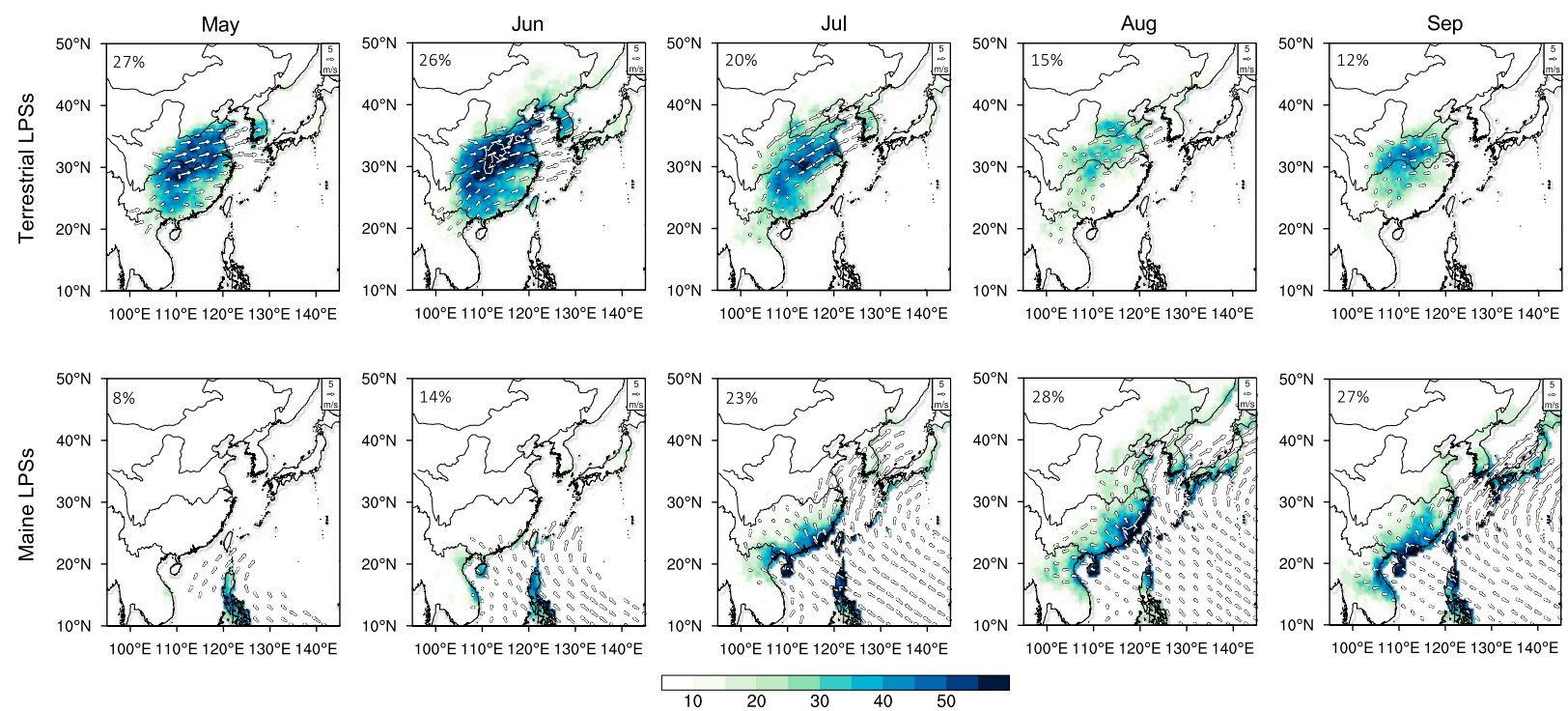

FIG. 11. Mean translation vectors ( $\mathrm{m} \mathrm{s}^{-1}$; arrows) and fractional contribution (\%; shading) of (top) terrestrial and (bottom) marine LPSs to the extreme precipitation exceeding 10-yr return period during (left to right) May, June, July, August, and September, respectively, based on the APHRODITE dataset. White contours start at $60 \%$ and have an interval of $10 \%$. The percentage of terrestrial and marine LPSs formed in each month with respect to the total seasonal number of LPSs is displayed in the upper left of each panel.

active in early summer (May-July) when their impact on extreme rainfall overwhelms that of the marine LPSs (Fig. 11, top), whereas the marine LPSs tend to occur more frequently in the late summer months (July-September) when the systems are more inclined to recurve northward and exert a significant impact on the East Asian coasts (Fig. 11, bottom). The seasonality aligns well with the changes in environmental conditions from early to late summer and is consistent with observational evidence (Chia and Ropelewski 2002; Feng et al. 2016). Specifically, the less frequent occurrence of terrestrial LPSs in late summer is associated with the northward migration of the westerly jet, which locates well north of the plateau during July-August and yields unfavorable conditions for lee cyclogenesis. The occurrence of marine LPSs is partially boosted by the warmer WNP SST in late summer. However, the trends of LPSs track density and associated rainfall are insensitive to the different definitions of the summer seasons (e.g., May-July for terrestrial LPSs and June-September for marine LPSs; not shown).

Our study links the synoptic-scale LPSs to the "south floodnorth drought" pattern of the observed summer extreme rainfall trend over the Southeast and East Asian monsoon regions. Compared to earlier studies from a seasonal perspective, understanding the link between LPSs and extreme rainfall provides a physical basis for the well-known trend pattern. Such a process-based approach may provide an effective way to assess the extreme rainfall changes and identify the underlying physical drivers. Note that here the linkages between LPSs and extreme rainfall trends are derived from observations, making it difficult to completely distinguish the LPS-related extreme rainfall and those associated with other larger-scale processes (e.g., monsoon trough). Idealized model simulations in which the LPSs can be artificially suppressed or enhanced could be helpful to confidently attribute the causes of extreme rainfall to LPSs.

On the other hand, given the spatial scale of LPSs, models are expected to better resolve these synoptic LPSs than the actual extreme rainfall, and thus changes in LPSs can be used to more realistically project extreme rainfall changes in the future. Further investigation with model experiments and models from phase 6 of the Coupled Model Intercomparison Project (CMIP6) models is warranted for a better understanding of the past and future extreme rainfall changes.

Acknowledgments. We thank Dr. Kelvin Hodges for making available the TRACK algorithm to the community and for valuable assistance in configuring that code. We would like to acknowledge the high-performance computing support from the High-Performance Computing Service at Columbia University, sponsored by the Columbia Center for Climate and Life. We thank three anonymous reviewers for their constructive and valuable suggestions. This research was supported by the National Science Foundation Grant AGS16-07348.

\section{REFERENCES}

Chang, C.-P., Y. Lei, C.-H. Sui, X. Lin, and F. Ren, 2012: Tropical cyclone and extreme rainfall trends in East Asian summer monsoon since mid-20th century. Geophys. Res. Lett., 39, L18702, https://doi.org/10.1029/2012GL052945.

Chia, H. H., and C. F. Ropelewski, 2002: The interannual variability in the genesis location of tropical cyclones in the northwest Pacific. J. Climate, 15, 2934-2944, https://doi.org/ 10.1175/1520-0442(2002)015<2934:TIVITG >2.0.CO;2. 
Chu, P.-S., J.-H. Kim, and Y. R. Chen, 2012: Have steering flows in the western North Pacific and the South China Sea changed over the last 50 years? Geophys. Res. Lett., 39, L10704, https:// doi.org/10.1029/2012GL051709.

Cohen, J. L., J. C. Furtado, M. Barlow, V. A. Alexeev, and J. E. Cherry, 2012: Asymmetric seasonal temperature trends. Geophys. Res. Lett., 39, L04705, https://doi.org/10.1029/2011GL050582.

Day, J. A., I. Fung, and W. Liu, 2018: Changing character of rainfall in eastern China, 1951-2007. Proc. Natl. Acad. Sci. USA, 115, 2016-2021, https://doi.org/10.1073/pnas.1715386115.

Dee, D. P., and Coauthors, 2011: The ERA-Interim reanalysis: Configuration and performance of the data assimilation system. Quart. J. Roy. Meteor. Soc., 137, 553-597, https://doi.org/ $10.1002 /$ qj. 828 .

Dong, Q., X. Chen, and T. X. Chen, 2011: Characteristics and changes of extreme precipitation in the Yellow-Huaihe and Yangtze-Huaihe River basins, China. J. Climate, 24, 37813795, https://doi.org/10.1175/2010JCLI3653.1.

Emori, S., and S. J. Brown, 2005: Dynamic and thermodynamic changes in mean and extreme precipitation under changed climate. Geophys. Res. Lett., 32, L17706, https://doi.org/ 10.1029/2005GL023272.

Feng, X.-Y., C.-H. Liu, G.-Z. Fan, X. D. Liu, and C. Y. Feng, 2016: Climatology and structures of southwest vortices in the NCEP Climate Forecast System Reanalysis. J. Climate, 29, 76757701, https://doi.org/10.1175/JCLI-D-15-0813.1.

Fu, S., J. Zhang, J. Sun, and X. Shen, 2014: A fourteen-year climatology of the southwest vortex in summer. Atmos. Oceanic Sci. Lett., 7, 510-514, https://doi.org/10.3878/AOSL20140047.

Guo, L., N. P. Klingaman, P. L. Vidale, A. G. Turner, M.-E. Demory, and A. Cobb, 2017: Contribution of tropical cyclones to atmospheric moisture transport and rainfall over East Asia. J. Climate, 30, 38533865, https://doi.org/10.1175/JCLI-D-16-0308.1.

He, C., T. Zhou, A. Lin, B. Wu, D. Gu, C. Li, and B. Zheng, 2015: Enhanced or weakened western North Pacific subtropical high under global warming? Sci. Rep., 5, 16771, https://doi.org/ 10.1038/srep16771.

Held, I. M., and B. J. Soden, 2006: Robust responses of the hydrological cycle to global warming. J. Climate, 19, 5686-5699, https://doi.org/10.1175/JCLI3990.1.

Hodges, K. I., 1994: A general method for tracking analysis and its application to meteorological data. Mon. Wea. Rev., 122, 2573-2586, https://doi.org/10.1175/1520-0493(1994)122<2573: AGMFTA $>2.0 . \mathrm{CO} ; 2$.

- 1995: Feature tracking on the unit sphere. Mon. Wea. Rev., 123, 3458-3465, https://doi.org/10.1175/1520-0493(1995)123<3458: FTOTUS>2.0.CO;2.

— 1999: Adaptive constraints for feature tracking. Mon. Wea. Rev., 127, 1362-1373, https://doi.org/10.1175/1520-0493(1999) $127<1362$ :ACFFT $>2.0 . \mathrm{CO} ; 2$.

Horton, D. E., N. C. Johnson, D. Singh, D. L. Swain, B. Rajaratnam, and N. S. Diffenbaugh, 2015: Contribution of changes in atmospheric circulation patterns to extreme temperature trends. Nature, 522, 465-469, https://doi.org/10.1038/ nature 14550.

Hoskins, B., and K. Hodges, 2002: New perspectives on the Northern Hemisphere winter storm tracks. J. Atmos. Sci., 59, 1041-1061, https://doi.org/10.1175/1520-0469(2002)059<1041: $\mathrm{NPOTNH}>2.0 . \mathrm{CO} ; 2$.

Hunt, K. M. R., A. G. Turner, P. M. Inness, D. E. Parker, and R. C. Levine, 2016: On the structure and dynamics of Indian monsoon depressions. Mon. Wea. Rev., 144, 3391-3416, https:// doi.org/10.1175/MWR-D-15-0138.1.
Hurley, J. V., and W. R. Boos, 2015: A global climatology of monsoon low-pressure systems. Quart. J. Roy. Meteor. Soc., 141, 1049-1064, https://doi.org/10.1002/qj.2447.

Ito, H., N. C. Johnson, and S. P. Xie, 2013: Subseasonal and interannual temperature variability in relationship to extreme temperature occurrence over East Asia. J. Climate, 26, 90269042, https://doi.org/10.1175/JCLI-D-12-00676.1.

Jiang, H., and E. Zipser, 2010: Contribution of tropical cyclones to the global precipitation from eight seasons of TRMM data: Regional, seasonal, and interannual variations. J. Climate, 23, 1526-1543, https://doi.org/10.1175/2009JCLI3303.1.

Khouakhi, A., G. Villarini, and G. A. Vecchi, 2017: Contribution of tropical cyclones to rainfall at the global scale. J. Climate, 30, 359-372, https://doi.org/10.1175/JCLI-D-16-0298.1.

Kim, I. W., J. Oh, S. Woo, and R. H. Kripalani, 2019: Evaluation of precipitation extremes over the Asian domain: Observation and modelling studies. Climate Dyn., 52, 1317-1342, https:// doi.org/10.1007/s00382-018-4193-4.

Knapp, K. R., M. C. Kruk, D. H. Levinson, H. J. Diamond, and C. J. Neumann, 2010: The International Best Track Archive for Climate Stewardship (IBTrACS). Bull. Amer. Meteor. Soc., 91, 363-376, https://doi.org/10.1175/2009BAMS2755.1.

Knight, D. B., and R. E. Davis, 2009: Contribution of tropical cyclones to extreme rainfall events in the southeastern United States. J. Geophys. Res., 114, D23102, https://doi.org/10.1029/ 2009JD012511.

Knutson, T. R., and Coauthors, 2010: Tropical cyclones and climate change. Nat. Geosci., 3, 157-163, https://doi.org/10.1038/ ngeo779.

Kossin, J. P., K. A. Emanuel, and G. A. Vecchi, 2014: The poleward migration of the location of tropical cyclone maximum intensity. Nature, 509, 349-352, https://doi.org/10.1038/ nature13278.

- ——, and S. J. Camargo, 2016: Past and projected changes in western North Pacific tropical cyclone exposure. J. Climate, 29, 5725-5739, https://doi.org/10.1175/JCLI-D-16-0076.1.

Li, R. C. Y., and W. Zhou, 2015: Interdecadal changes in summertime tropical cyclone precipitation over southeast China during 1960-2009. J. Climate, 28, 1494-1509, https://doi.org/ 10.1175/JCLI-D-14-00246.1.

Liang, A., L. Oey, S. Huang, and S. Chou, 2017: Long-term trends of typhoon-induced rainfall over Taiwan: In situ evidence of poleward shift of typhoons in western North Pacific in recent decades. J. Geophys. Res. Atmos., 122, 2750-2765, https:// doi.org/10.1002/2017JD026446.

Lin, R., T. Zhou, and Y. Qian, 2014: Evaluation of global monsoon precipitation changes based on five reanalysis datasets. J. Climate, 27, 1271-1289, https://doi.org/10.1175/JCLI-D-13-00215.1.

Liu, B., M. Xu, M. Henderson, and Y. Qi, 2005: Observed trends of precipitation amount, frequency, and intensity in China,19602000. J. Geophys. Res., 110, D08103, https://doi.org/10.1029/ 2004JD004864.

Ma, S., T. Zhou, A. Dai, and Z. Han, 2015: Observed changes in the distributions of daily precipitation frequency and amount over China from 1960 to 2013. J. Climate, 28, 6960-6978, https:// doi.org/10.1175/JCLI-D-15-0011.1.

Mann, H. B., 1945: Nonparametric tests against trend. Econometrica, 13, 245-259, https://doi.org/10.2307/1907187.

Murakami, H., B. Wang, T. Li, and A. Kitoh, 2013: Projected increase in tropical cyclones near Hawaii. Nat. Climate Change, 3, 749-754, https://doi.org/10.1038/nclimate1890.

O'Gorman, P. A., and T. Schneider, 2009: The physical basis for increases in precipitation extremes in simulations of 21st-century 
climate change. Proc. Natl. Acad. Sci. USA, 106, 14773-14777, https://doi.org/10.1073/pnas.0907610106.

Pfahl, S., and H. Wernli, 2012: Quantifying the relevance of cyclones for precipitation extremes. J. Climate, 25, 6770-6780, https://doi.org/10.1175/JCLI-D-11-00705.1.

— , P. A. O'Gorman, and E. M. Fischer, 2017: Understanding the regional pattern of projected future changes in extreme precipitation. Nat. Climate Change, 7, 423-427, https://doi.org/ 10.1038/nclimate3287.

Ren, F., G. Wu, W. Dong, X. Wang, Y. Wang, W. Ai, and W. Li, 2006: Changes in tropical cyclone precipitation over China. Geophys. Res. Lett., 33, L20702, https://doi.org/10.1029/ 2006GL027951.

Sardeshmukh, P. D., and B. J. Hoskins, 1984: Spectral smoothing on the sphere. Mon. Wea. Rev., 112, 2524-2529, https://doi.org/ 10.1175/1520-0493(1984)112<2524:SSOTS > 2.0.CO;2.

Sato, T., and T. Nakamura, 2019: Intensification of hot Eurasian summers by climate change and land-atmosphere interactions. Sci. Rep., 9, 10866, https://doi.org/10.1038/s41598-019-47291-5.

Sharmila, S., and K. Walsh, 2018: Recent poleward shift of tropical cyclone formation linked to Hadley cell expansion. Nat. Climate Change, 8, 730-736, https://doi.org/10.1038/s41558018-0227-5.

Singh, D., S. Ghosh, M. K. Roxy, and S. McDermid, 2019: Indian summer monsoon: Extreme events, historical changes, and role of anthropogenic forcings. Wiley Interdiscip. Rev.: Climate Change, 10, e571, https://doi.org/10.1002/wcc.571.

Tao, S.-Y., 1980: The Heavy Rainfalls in China. Science Press, 225 pp.

, and Y. Ding, 1981: Observational evidence of the influence of the Qinghai-Xizang (Tibet) Plateau on the occurrence of heavy rain and severe convective storms in China. Bull. Amer. Meteor. Soc., 62, 23 30, https://doi.org/10.1175/1520-0477(1981)062<0023: OEOTIO $>2.0 . \mathrm{CO} ; 2$.

Tu, J. Y., C. Chou, and P. S. Chu, 2009: The abrupt shift of typhoon activity in the vicinity of Taiwan and its association with western North Pacific-East Asian climate change. J. Climate, 22, 3617-3628, https://doi.org/10.1175/2009JCLI2411.1.

Vecchi, G. A., and T. R. Knutson, 2008: On estimates of historical North Atlantic tropical cyclone activity. J. Climate, 21, 35803600, https://doi.org/10.1175/2008JCLI2178.1.

Wang, B., and I. Orlanski, 1987: Study of a heavy rain vortex formed over the eastern flank of the Tibetan Plateau. Mon. Wea. Rev., 115, 1370-1393, https://doi.org/10.1175/1520-0493(1987) $115<1370:$ SOAHRV $>2.0$. CO; 2 .
_ J. Jiu, H.-J. Kim, P. J. Webster, and S.-Y. Yim, 2012: Recent change of the global monsoon precipitation (1979-2008). Climate Dyn., 39, 1123-1135, https://doi.org/10.1007/s00382011-1266-z.

Wang, W., Y.-H. Kuo, and T. T. Warner, 1993: A diabatically driven mesoscale vortex in the lee of the Tibetan Plateau. Mon. Wea. Rev., 121, 2542-2561, https://doi.org/10.1175/15200493(1993)121<2542:ADDMVI>2.0.CO;2.

Wang, Y., and L. Zhou, 2005: Observed trends in extreme precipitation events in China during 1961-2001 and the associated changes in large-scale circulation. Geophys. Res. Lett., 32, L09707, https://doi.org/10.1029/2005GL023769.

$\mathrm{Wu}, \mathrm{G}$., and Coauthors, 2007: The influence of mechanical and thermal forcing by the Tibetan Plateau on Asian climate. J. Hydrometeor., 8, 770-789, https://doi.org/10.1175/JHM609.1.

Wu, L., B. Wang, and S. Geng, 2005: Growing typhoon influence on East Asia. Geophys. Res. Lett., 32, L18703, https://doi.org/ 10.1029/2005GL022937.

Yang, L., S. Chen, C. Wang, D. Wang, and X. Wang, 2018: Potential impact of the Pacific decadal oscillation and sea surface temperature in the tropical Indian Ocean-western Pacific on the variability of typhoon landfall on the China coast. Climate Dyn., 51, 2695-2705, https://doi.org/10.1007/ s00382-017-4037-7.

Yatagai, A., K. Kamiguchi, O. Arakawa, A. Hamada, N. Yasutomi, and A. Kitoh, 2012: APHRODITE: Constructing a long-term daily gridded precipitation dataset for Asia based on a dense network of rain gauges. Bull. Amer. Meteor. Soc., 93, 14011415, https://doi.org/10.1175/BAMS-D-11-00122.1.

Yokoi, S., Y. N. Takayabu, and H. Murakami, 2013: Attribution of projected future changes in tropical cyclone passage frequency over the western North Pacific. J. Climate, 26, 4096-4111, https://doi.org/10.1175/JCLI-D-12-00218.1.

You, Q., and Coauthors, 2011: Changes in daily climate extremes in China and their connection to the large-scale atmospheric circulation during 1961-2003. Climate Dyn., 36, 2399-2417, https://doi.org/10.1007/s00382-009-0735-0.

Zhai, P., X. Zhang, H. Wan, and X. Pan, 2005: Trends in total precipitation and frequency of daily precipitation extremes over China. J. Climate, 18, 1096-1108, https://doi.org/10.1175/ JCLI-3318.1.

Zhang, Q., Y. Lai, X. Gu, P. Shi, and V. P. Singh, 2018: Tropical cyclonic rainfall in China: Changing properties, seasonality and causes. J. Geophys. Res. Atmos., 123, 4476-4489, https:// doi.org/10.1029/2017JD028119. 